\title{
Model of Fracture, Friction, and Wear Phenomena of Porous Iron
}

\author{
A. A. Shatsov, I. V. Ryaposov, and D. M. Larinin \\ Mechanical Technological Faculty, State National Research Politechnical University of Perm, \\ 29 Komsomolskii Avenue, Perm 614990, Russia \\ Correspondence should be addressed to A. A. Shatsov, shatsov@pstu.ru
}

Received 16 June 2011; Revised 8 September 2011; Accepted 8 September 2011

Academic Editor: Luca Settineri

Copyright () 2011 A. A. Shatsov et al. This is an open access article distributed under the Creative Commons Attribution License, which permits unrestricted use, distribution, and reproduction in any medium, provided the original work is properly cited.

\begin{abstract}
Mechanical and tribotechnical features of powdered materials are strongly influenced by pore volume, fracture character, impurities, alloying, concentration inhomogeneity, friction conditions, and other factors. Pores also have influence on acceleration of diffusion processes and reduce undercooled austenite resistance. Annealed in hydrogen, ultra pure iron powder was used to study porous iron features. Toughness fracture and tribotechnical features had nonmonotonic dependence from porosity different from all known dependences got from technical iron powders. Researches brought out the fact that in process of porosity reduction by pressing and annealing cycles, the average dimension of porous is changed. According to the analysis of porous structure were created models of friction, wear, and fracture of pure porous iron.
\end{abstract}

\section{Introduction}

The last few decades studies conducted in highly technologically developed countries showed that proper choice of friction pairs from the position of tribology could save approximately $1.5 \%$ of national income [1]. The usage of powdered materials best of all suits to the conditions of economic feasibility, because it allows to replace expensive and scarce alloys, increase productivity, and vacate production space. For example, the presence of residual pores in the structure of the bearing material can increase details' durability from 1.5 to 10 times [2].

There are three groups of the main factors influencing the friction: technological (structure, mechanical, and physical properties), constructive (contact scheme, the macro- and microgeometry, surface friction), and operational (specific friction work, sliding velocity, specific load, temperature, presence of grease, medium).

The friction process causes the formation of surface and subsurface layers which are conditioned by one or another friction and wear mechanism.

The last years researches were aimed at mechanical characteristics determination, including fracture strength and its connection with tribotechnical and physical features [3-22].

The aim of this work is to investigate and to model the friction, wear, and fracture processes of ultrapure iron.

\section{Fracture Toughness of Ultrapure Porous Iron}

Dependence of fracture toughness $K_{\mathrm{IC}}$ and strength on porosity $P$ is not always strictly monotonic function $[3,4]$. Defining this dependence is necessary for both theoretical concepts of crack interaction with defects and for specific practical problems solution, for example, the choice of the porosity of construction products, which can provide the highest fracture toughness. The main condition for determining reliability of $K_{\mathrm{IC}}$ is the proof of the crack propagation in plane strain. This requirement imposes limitations on sample size and crack length. Crack length should be at least $2 \mathrm{~mm}$ and together with a groove to be $0.45-0.55$ height of the specimen (GOST 25.506-85). The height of the sample is usually taken $12 \mathrm{~mm}$. According to the regulations, the most exacting requirements are imposed on the thickness, which should not be less than $\beta\left(K_{\mathrm{IC}} / \sigma_{0.2}\right)^{2}$, where $\beta=2.5$. However, other factors like the flat fracture and absence of thinning edges and lips cut, even if the porosity of iron have a few percent, indicate the reliability of the results. Thus, for the iron of high purity factor of proportionality $\beta$ and the ratio between the thickness to $\left(K_{\mathrm{IC}} / \sigma_{0.2}\right)^{2}$ was $0.3-0.4$ [23] for powder Ni-Mo-Cu steel $\beta=1.6$ [24]; for high-ductility stainless steel at $P=5 \%, \beta=0.04$ [25]; for nickel steels $\beta=1.4[26]$. 
TABLE 1: The dependence of powder materials fracture toughness on porosity and sample thickness.

\begin{tabular}{|c|c|c|c|c|c|}
\hline $\begin{array}{l}\text { Number of the } \\
\text { composition }\end{array}$ & Composition & $\begin{array}{l}\text { Atmosphere and } \\
\text { sintering mode }\end{array}$ & Porosity, \% & $\begin{array}{c}\text { The sample } \\
\text { thickness, mm }\end{array}$ & $\begin{array}{c}\text { Fracture toughness, } \\
\mathrm{MN} / \mathrm{m}^{3 / 2}\end{array}$ \\
\hline 1 & & & 15 & 2.80 & 9.5 \\
\hline & & & & 4.60 & 10.0 \\
\hline 2 & \multirow{5}{*}{ PZh4M2 } & \multirow{4}{*}{ Vacuum, $1200^{\circ} \mathrm{C}, 2 \mathrm{~h}$} & 13 & $\begin{array}{c}\text { Sample sizes: } \\
40 \times 18.4 \times 90 \mathrm{~mm}\end{array}$ & 10.0 \\
\hline 3 & & & 10 & 5.50 & 10.5 \\
\hline 4 & & & 9 & 6.45 & 10.0 \\
\hline 5 & & & 10 & 9.75 & 9.5 \\
\hline 6 & & \multirow{4}{*}{ Hydrogen, $1200^{\circ} \mathrm{C}, 2 \mathrm{~h}$} & 3.6 & 4.30 & 23.9 \\
\hline 7 & \multirow{3}{*}{ OsCh 6-2 } & & 4.0 & 7.55 & 23.8 \\
\hline 8 & & & 7.3 & 4.80 & 19.1 \\
\hline 9 & & & 7.5 & 9.10 & 18.9 \\
\hline
\end{tabular}

Note: The iron grade OSCh 6-2-the average particle size is $5 \mu \mathrm{m}$, the carbon content is less than $0.02 \%$ in mass, the total concentration of other impurities is less than $0.001 \%$.

The correctness of the definition of $K_{\mathrm{IC}}$ was examined by varying the thickness of the samples (Table 1). For sample thickness ranging from 4.3 to $9.1 \mathrm{~mm}, \beta$ varies from 0.2 to 5.5. The obtained values are within the limits of the measurement inaccuracy confidence interval, which gives grounds to take $K_{Q}$ for $K_{\mathrm{IC}}$. In all cases the sample thickness of $3 \mathrm{~mm}$ provided a satisfactory convergence of the results.

The data (Table 1) prove the invariance of fracture strength to a sample thickness. However, this does not mean that $K_{\mathrm{IC}}$ is invariant to the sample size for all porous steels and alloys, therefore, the influence of size ratios on the $K_{Q}$ should be determined experimentally for different materials.

The choice of ultrapure iron is connected to a necessity to minimize the unanswered effect of impurities. Other important factors determining the fracture toughness are fracture mode, porosity, composition, and heterogeneity of alloying elements. Most of these factors which influence the $K_{\mathrm{IC}}(P)$ dependence could be eliminated by the selection of the material and the sample fabrication method. The effect of porosity on fracture toughness data cited in the literature is contradictory. For example, a nonmonotonic dependence of $K_{\mathrm{IC}}$ on $P$ at room temperature and at $-180^{\circ} \mathrm{C}$ was determined [27]. A monotonic dependence $K_{\mathrm{I} C}(P)$ has been noticed by other authors $[23,25,26,28-32]$.

The authors of [21] do not exclude that the appearance of nonmonotonic $K_{\mathrm{IC}}(P)$ dependence is associated with redistribution of impurities, because the situation of high porosity it is energetically favorable for the impurities to locate at the free surface of the pores, as well as the seals they move into the matrix, concentrating at grain boundaries, thus reduce the level of fracture toughness.

Studies have shown [33] that comparing with the porosity, the more significant factor affecting the fracture toughness is the proportion of interparticle destruction; also a linear correlation between $K_{\mathrm{IC}}$ and the proportion of transgranular cleavage (test temperature minus $196^{\circ} \mathrm{C}$ ) was established.

Carbonyl iron OSCh 6-2 was annealed 1 hour in hydrogen at $450^{\circ} \mathrm{C}$ before pressing to minimize the influence of impurity atoms. The oxygen content weight in sintered samples of the iron did not exceed $0.01 \%$.

For stochastically inhomogeneous bodies fracture toughness could be accurately estimated using the effective stress intensity factor $K_{\mathrm{IC}}$ [34]. The structure of the sintered iron powder is a single-phase material containing pores of various sizes.

Fracture toughness of iron samples (PZh4M2) with porosity $10-16 \%$ practically coincides with that one given in [33]. The porosity reduction is accompanied by a change from interparticle to transgranular ductile fracture mode (Figure 1). Therefore, a monotonic $K_{\mathrm{IC}}$ increase is associated with a reduction of the proportion of intercrystallite fracture due to increased interparticle metallic bonds. For the iron samples, a correlation between $K_{\mathrm{IC}}$ and mechanical properties was established (Figure 2).

The relationship between intercrystallite and intragranular fracture components depends on the sintering atmosphere. Thus, after sintering at $1200^{\circ} \mathrm{C}, 4 \mathrm{~h}$ in vacuum the fracture toughness of the $10 \%$ porosity samples was 10 $11 \mathrm{MN} / \mathrm{m}^{3 / 2}$ and fracture mode was intercrystallite. After the same sintering in hydrogen, the fracture toughness of the same porosity iron samples (PZh4M2) was 20$21 \mathrm{MN} / \mathrm{m}^{3 / 2}$, and fracture mode was transgranular. Other mechanical properties increased less significantly: $\sigma_{B}$ from 180 to $320 \mathrm{MPa}, \sigma_{0.2}$ from 100 to $140 \mathrm{MPa}$, and $\delta$ from 10 to $16 \%$.

$K_{\mathrm{IC}}$ values for samples of iron OSCh 2-6 were higher and the dependence of $K_{\mathrm{IC}}$ on $P$ (from 3 to $7 \%$ ) was nonmonotonic. Fracture mode was intragranular regardless of porosity (Figures 3, 4, 5, and 6). The detailed fractographs study revealed that the highest proportion of cleavage on the fracture surface was in the samples with $3.5-4 \%$ porosity. It corresponds to the inflection point of the fracture toughness on porosity dependence. The porosity changes leads to an increase of the ductile component of the fracture surface, and $P=6 \%$ of the sites of cleavage fracture were not observed. With increasing porosity, pits were less deep and surface resembled a honeycomb fracture [35]. 


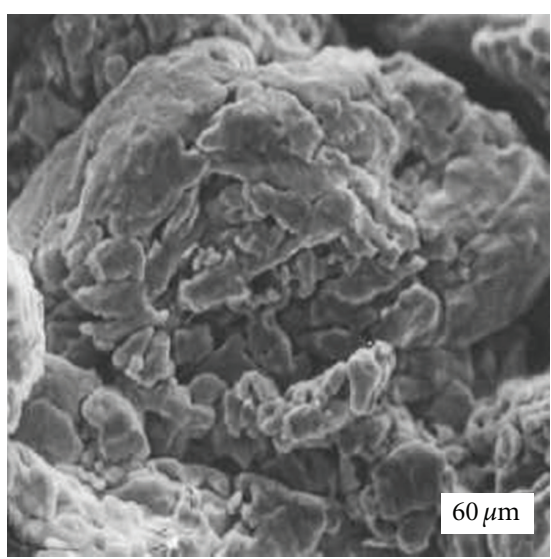

(a)

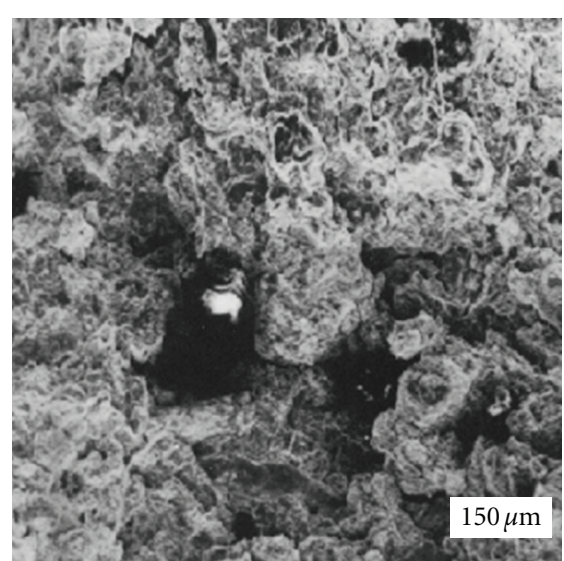

(b)

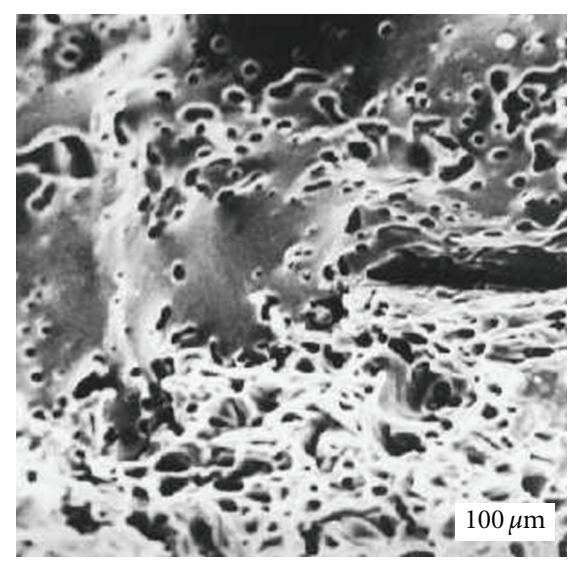

(c)

Figure 1: Fractography of the iron grade PZh4M2 specimens: (a) after pressing, $\times 500$; (b) $P=18 \%, \times 200 ;(\mathrm{c}) P=10 \%, \times 700$.

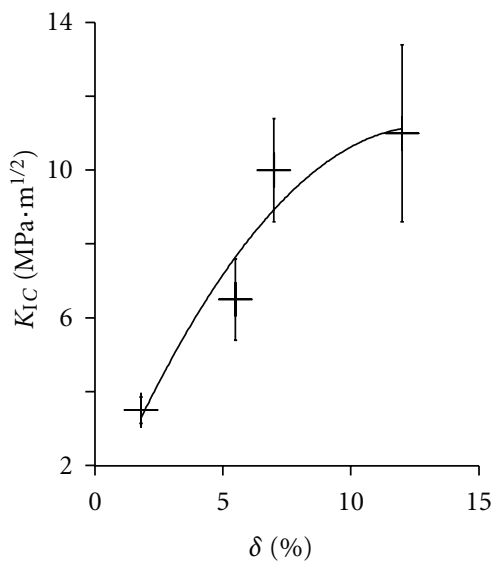

(a)

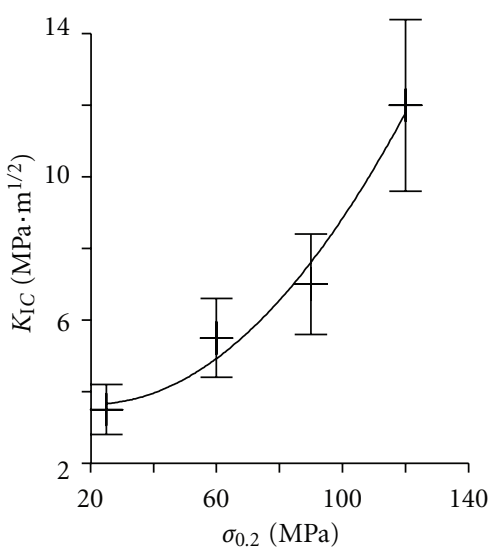

(b)

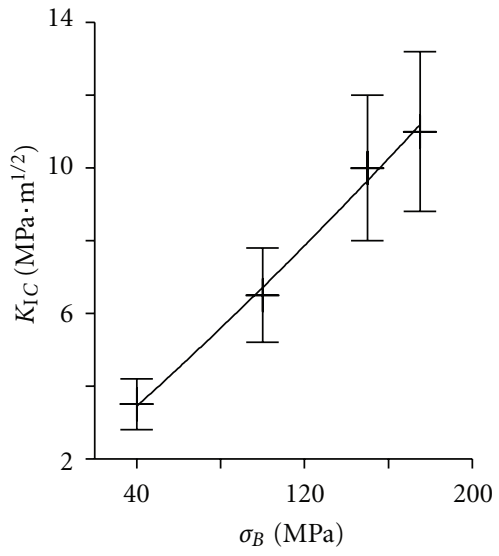

(c)

FIGURE 2: Mechanical properties and fracture toughness correlation of vacuum sintered samples from technical iron PZh4M2 grade.

Thus, the change in the ratio of ductile and cleavage component is a mechanism for implementing nonmonotonic $K_{\mathrm{I} C}(P)$ dependence. But to understand the process of destruction of the porous body it is necessary to develop the model representations that connect fracture toughness to the characteristics of the porous structure.

Reduction of impurities concentration in the iron powder does not change $K_{\mathrm{IC}}(P)$ dependence type, so one can assume that nonmonotonic decrease of $K_{\mathrm{IC}}$ is the result of the interaction of cracks with the pores. This result is consistent with theoretical studies [22, 36, 37], proving the possibility of a nonmonotonic change of $K_{\text {IC }}$ by varying the structural defects.

Attention is drawn to the increased size of pores at $P=3.5 \%$, which corresponds to a singular point of $K_{\mathrm{IC}}(P)$ dependence (Table 2). This fact gives a reason to suggest a relationship between fracture toughness and pore size distribution and, hence, the distance between the pores. Apparently, the influence of pores on the fracture toughness is not only due to the average porosity.
To describe the interaction of crack with pores its movement can be represented as the movement of a dislocation front. Reasons to study the propagation of the crack front by analogy with the dislocation front directly for pure iron are given in [38].

We assume that the pores are spherical, uniformly distributed and separated by a distance $2 R$. Crack bending leads to a change in its distribution energy [39-41]:

$$
\begin{aligned}
& g^{\prime}=g+\frac{T}{R}, \\
& K_{\mathrm{IC}}=\sqrt{\frac{E \cdot g^{\prime}}{1-\mu^{2}}}=\sqrt{\frac{E}{1-\mu^{2}}\left(g+\frac{T}{R}\right)},
\end{aligned}
$$

where $g$ is the crack distribution energy; $T$-linear crack front tension; $E$-elastic modulus; $\mu$-Poisson's ratio.

Expanding (1) in a series, since $g \gg T$, we find

$$
K_{\mathrm{IC}}=K_{\mathrm{IC}}^{0}(P)+\frac{1}{2} \frac{E \cdot T}{\left(1-\mu^{2}\right) \cdot K_{\mathrm{IC}}(P) \cdot R} .
$$




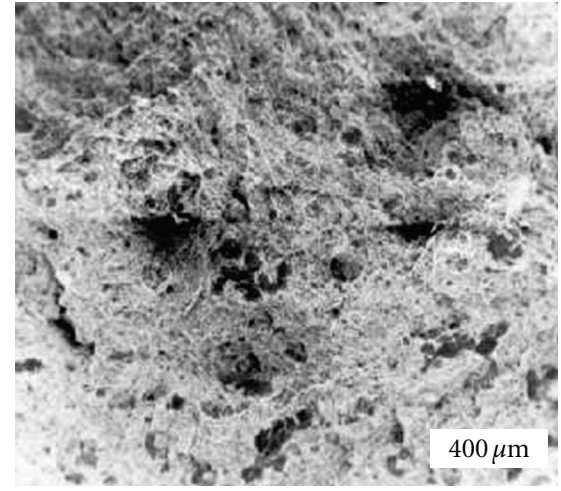

(a)

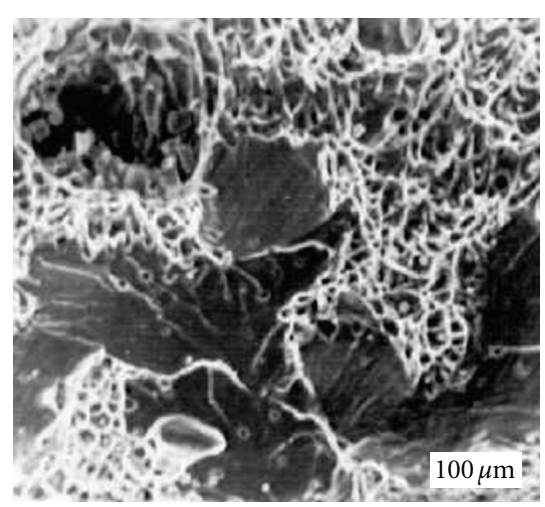

(b)

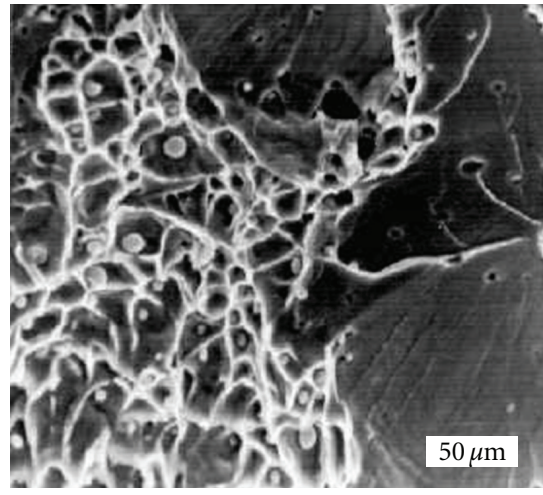

(c)

FIgURE 3: Fractography of the iron grade OSCh $6-2$ with $2 \%$ porosity specimens: (a) $\times 75$; (b) $\times 400$; (c) $\times 750$.

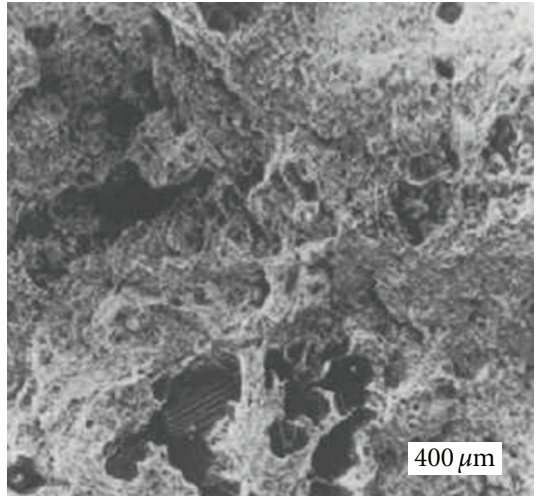

(a)

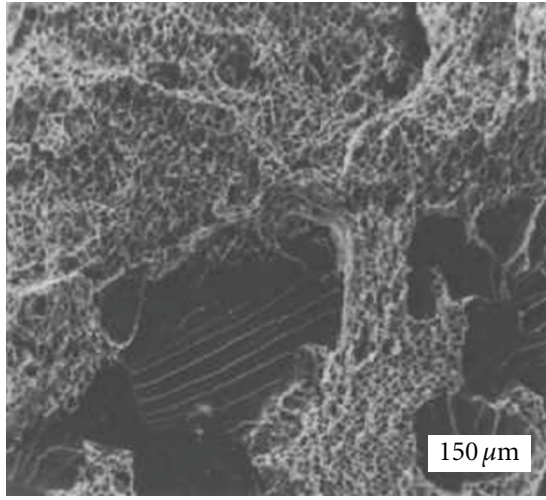

(b)

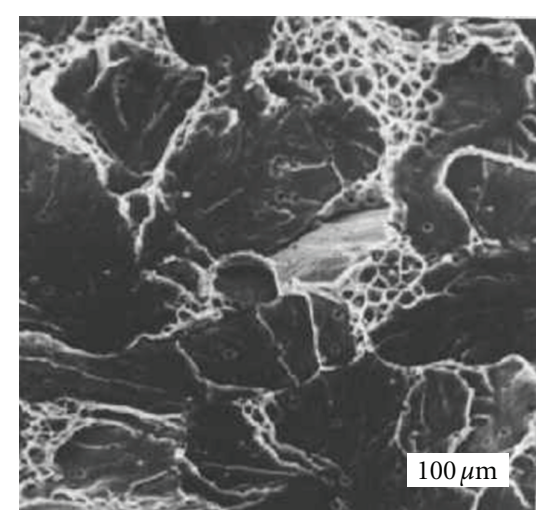

(c)

FIGURE 4: Fractography of the iron grade OSCh $6-2$ with $3.6 \%$ porosity specimens: (a) $\times 75$; (b) $\times 200$; (c) $\times 400$.

Equation (4) is got in correlation assumption of specific energy of uniform deformation $(A)$ and effective surface energy $\left(\gamma_{\text {eff }}\right)$ of the Griffiths-Orowan theory [42]:

$$
\begin{gathered}
K_{\mathrm{IC}}^{0}=\sqrt{\frac{0.8 \cdot l_{d} \cdot A \cdot E}{1-\mu^{2}}}, \\
A=\frac{\left(\delta_{\mathrm{e}}-\sigma_{0.2} / E\right) \cdot\left(\sigma_{0.2}+2 \sigma_{B}\right)}{3}+\frac{\sigma_{0.2}^{2}}{2 E},
\end{gathered}
$$

where $l_{d}$-length dimension constant; $\delta_{e}$ - uniform deformation; $\sigma_{0.2}$ and $\sigma_{B}$ yield strength and tensile strength, respectively.

$l_{d}$ is a constant in the limit $P \rightarrow 0$. Extrapolation of experimental data to zero porosity gives $K_{\mathrm{IC}}=35 \mathrm{MN} / \mathrm{m}^{3 / 2}$, $\sigma_{0.2}=250 \mathrm{MPa}, \sigma_{B}=350 \mathrm{MPa}, \delta=49 \%$, and $\delta_{e}=26 \%$. Similar values of mechanical properties obtained in [43-45].

Then we calculate $K_{\mathrm{IC}}^{0}$ for all porosity values:

$K_{\mathrm{IC}}^{0}$

$=\sqrt{\frac{0.4 \cdot 10^{-3}\left[2\left(\delta_{e}(P) \cdot E(P)-\sigma_{0.2}(P)\right) \cdot\left(\sigma_{0.2}(P)+2 \sigma_{B}(P)+3 \sigma_{0.2}(P)\right)\right]}{3\left[1-\mu^{2}(P)\right]}}$.
Dependence $\mu=\mu(P)$ was established in [46]:

$$
\mu(P)=\frac{(1-P) \mu}{1-P \mu} .
$$

For the iron powder [47]:

$$
E(P)=E(1-P)^{3 / 4} .
$$

As a result of fitting the experimental data by (3) we determined the value of $T=3 \cdot 10^{-4} \mathrm{~N}$. Average approximation accuracy $(4 \%)$ indicates a good convergence of calculated and experimental results. The crack front tension can be determined directly from the expression:

$$
T=\tau \cdot R,
$$

where $\tau$-crack movement stress.

The general idea is that the crack movement through the area with obstacles in it can be described on the assumption of the same principles as in dislocation movement which is described in details in [48] and later in [49]. The possibility of the crack movement is proved experimentally in [50]. In this case porous were studied as inhomogeneities (second phase). The equation was got in assumption of minimal front 


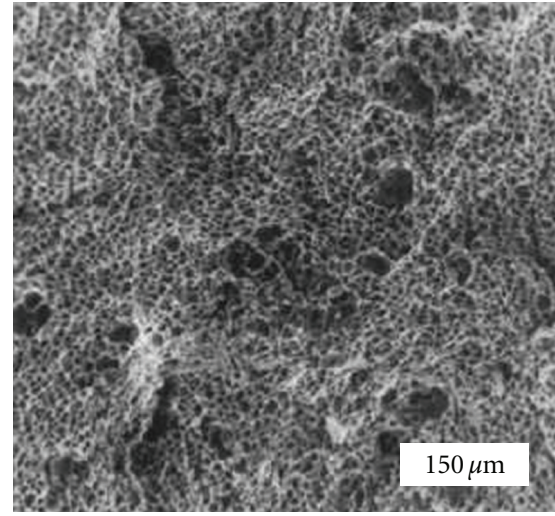

(a)

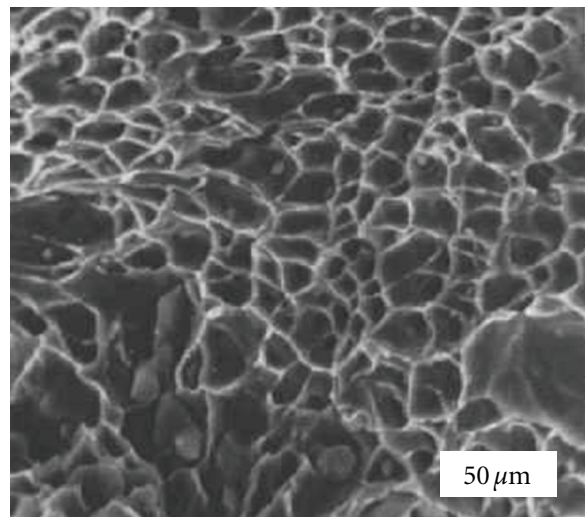

(b)

FIGURE 5: Fractography of the iron grade OSCh $6-2$ with $5.9 \%$ porosity specimens: (a) $\times 200$; (b) $\times 750$.

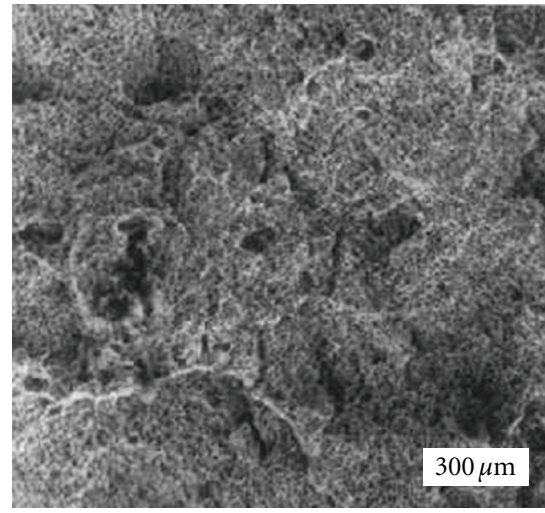

(a)

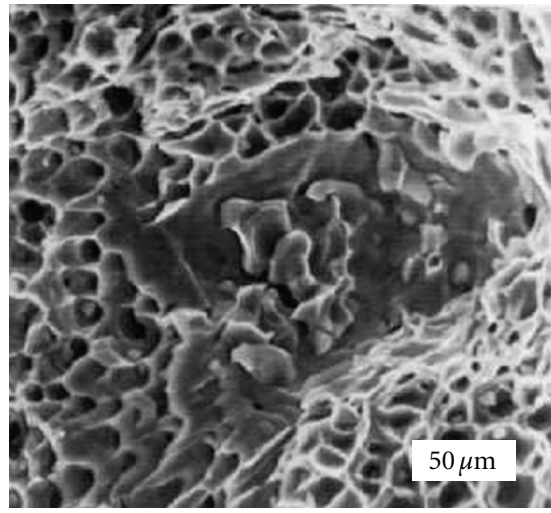

(b)

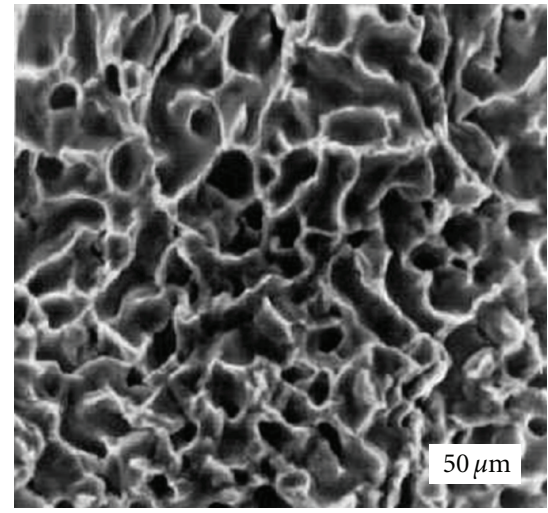

(c)

FiguRE 6: Fractography of the iron grade OSCh $6-2$ with $7.3 \%$ porosity (a, b) and with $20 \%$ porosity (c) specimens: (a) $\times 100$; (b) $\times 750$; (c) $\times 750$.

bend of the crack in condition of relatively large porous and long distance between them,

$$
\tau=\frac{r^{2} \cdot \pi \cdot \Gamma}{2 b_{0} \cdot \Omega}
$$

where $r$-pore radius; $\Gamma$-interface energy; $\Gamma=1000$ ergs $/$ $\mathrm{cm}^{2}[51] ; b_{0}$-interatomic distance; $b_{0}=0.246 \cdot 10^{-9} \mathrm{~m} ; \Omega$ distance between the inhomogeneities (pores).

Then, as the porosity, for example $P=7.5 \%, T$ is equal to $2.5-25 \cdot 10^{-4} \mathrm{~N}$, which is higher than, but has the same order with, a value of $T$, determined experimentally. The coincidence of the front crack tension value found experimentally and calculated from published data confirms the validity of expression (3).

As seen from (3), for effective crack interaction with the defects it is necessary that the distance between the defects was several times shorter than the size of the crack, the same view expressed in [51].

Thus, the nonmonotonic dependence of fracture toughness on porosity was established and when the effect of impurities is minimal. It was shown that the type of $K_{\mathrm{IC}}(P)$ dependence is the result of crack interaction with pore system, the maximum percentage of cleavage on the fracture surface coincides with a singular point of $K_{\mathrm{IC}}(P)$ dependence.

A model explaining the deviation from a strictly monotonic decrease of fracture toughness with increasing porosity by crack front tension and allowing to predict fracture toughness of powder materials is given.

Note that the characteristics of plasticity may also have nonmonotonic dependence on porosity $[51,52]$.

\section{Influence of Pores on the Friction and Wear of Iron}

Mechanics of contact fracture offers a solution to the problem of wear for a half-space of moving on its surface Hertz plateau in the presence of horizontal and vertical cracks [53]. However, the features of porous materials allow to use a simple functional relation to the conservation of acceptable accuracy in many cases. First of all, if we proceed from the principle of superposition, for small friction ratio the contribution of the tangential component $\tau_{z}=-f q(x)$ is small. For example, increasing of the contour pressure on the order during sliding friction without lubrication of 
TABLE 2: The dependence of porosity on the mechanical properties of OSCh 6-2 iron.

\begin{tabular}{|c|c|c|c|c|c|}
\hline Porosity, \% & Average pore diameter, microns & $\sigma_{0.2}$ & $\sigma_{B}$ & $\delta$ & $\delta_{e}$ \\
\hline 2.7 & 1.2 & 215 & 328 & 41 & 18 \\
\hline 3.5 & 2.0 & 170 & 301 & 30 & 12 \\
\hline 6.0 & 1.4 & 162 & 293 & 29 & 12 \\
\hline 7.5 & 1.7 & 130 & 240 & 26 & 10 \\
\hline 12.7 & - & 125 & 235 & 25 & 9.2 \\
\hline 20 & 1.8 & 71 & 151 & 12 & 4.5 \\
\hline
\end{tabular}

oil-impregnated steel PA-ZhGr1 with $20 \%$ porosity results in $f$ changes only by $17 \%$ and the wear rate-on the order. Secondly, the problem is solved for certain contact surfaces. At the same contact type, changes of $f$ are relatively small (compared to the differences between the friction ratios for different interactions types), and porous materials have the same trend. Relationship between wear rate and the variable parameters (especially pressure) within the proposed solutions were selected empirically using the coefficients that indirectly takes into account the contribution of the friction ratio.

Physico-mechanical and antifrictional properties of heterogeneous powder materials depend on several factors which are the chemical composition, heat treatment, variations in the density and distribution of alloying elements, content and distribution of related impurities, and so forth.

Some factors mentioned could be eliminated as a result of using pure iron [21, 54, 55]. But high content of impurities in industrial iron powder, insufficient porous structure description, and narrow ranges of the test pressure variation are the reasons of determination impossibility of the contribution of each measured parameters with high reliability.

The dependence of friction ratio $f$ and wear rate on the porosity $P$ and the pressure $P_{n}$ were studied in wide ranges $\left(P=2-20 \%, P_{n}=0.25-4.2 \mathrm{MPa}\right)$ for samples of pure iron (OSCh 6-2). Porosity was decreased by cycles of repressing and annealing. The size distribution of wear particles (Figure 7) were studied by microscope "Neophot21". Distribution shows that wear fractions are considerably smaller then porous (Table 2) and can influence on friction conditions, the forming surface geometry, and it can influence especially strongly on oil layers appearance during boundary friction of infiltrated with oil samples.

Friction surface was studied by scanning microscope SEM-200 (Figure 8). Tribological properties were determined by SMC-2, with hardened steel 45 (GOST 26614-85) as a friction pair. X-ray diffraction analysis was made on a DRON-2 in the $\lambda$-Co radiation.

On the friction surfaces, inclusions (presumably oxides) and microcutting traces were found, Figure 8 . Such surfaces are typical for powder compacts, working at hard conditions. The friction ratio has a pronounced nonmonotonic dependence on the porosity with a maximum about $P=4 \%$, which coincides with the minimum of $K_{\mathrm{IC}}(P)$ dependence.

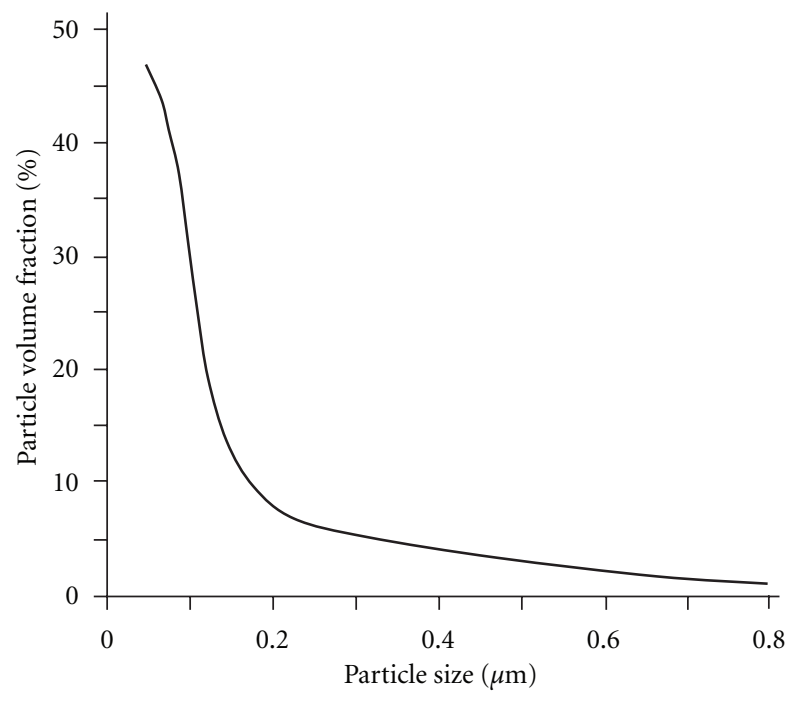

Figure 7: The size distribution of wear particles.

Since there is a correlation between friction ratio and wear characteristics, and wear resistance is related to pore size [56], it can be assumed that the local extremum of $f(P)$ is also associated with the peculiarities of the porous structure.

Narrow ranges of friction ratio variation allow to suggest prorated relationship between contour $\left(P_{c}\right)$ and nominal pressure $\left(P_{n}\right)[57,58]$.

The experimental data was treated as follows. For each value of porosity, friction ratio deformation component $f_{d}$ [59] was calculated (11), suggesting that the conditions of the unsaturated plastic contact would be met. The equation was got in assumption of an additive contribution of molecular and deformative component of friction force. Deformative component is caused by the deformation of a less hard body by a harder one:

$$
f_{d}=0.5 \Delta^{1 / 2}\left(\frac{P_{c}}{\mathrm{HB}}\right)^{0.25} \approx\left(C \cdot \frac{P_{n}}{\mathrm{HB}}\right)^{0.25}
$$

where $\Delta-$ microroughnesses characteristic of a rigid material of the friction pair, $P_{c}$-contour pressure, and $\mathrm{HB}-$ hardness, $C$-constant. The value of $\Delta$ was in the range $10^{-1}-10^{-3}[59]$. 


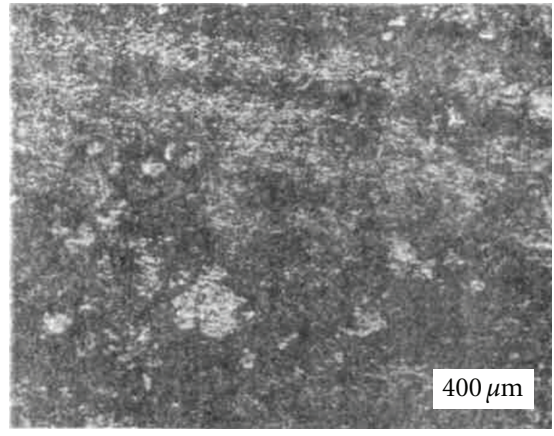

(a)

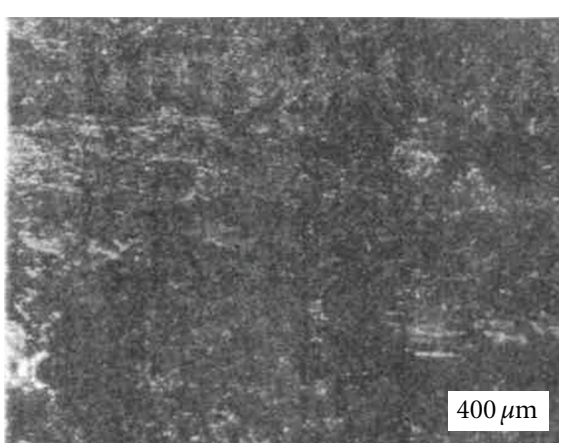

(b)

FIGURE 8: Friction surface of porous iron OSCh 6-2 specimen, $\times 50$ : (a) $2 \%$ porosity, (b) $20 \%$ porosity.

Type of mechanical treatment determines the value of the microroughnesses characteristic. The pressure $P$ and the hardness values are shown in Table 3.

In the first approximation, the molecular component of friction ratio $f_{m}$ decreases proportional to $(1-P)$, since $f_{m}$ is proportional to the area $A$, where shear stresses $\tau$ appear. This is due to the fact that the pore size (several microns) in 1-2 orders of magnitude higher than the arithmetic mean deviation of profile $\mathrm{Ra}=0.09$ micron, hence, the contact between the surfaces in the area of the pores is unlikely. For a porous material [59], assuming $f_{m}$ decreasing in $(1-P)$ times and the proportionality of $P_{n}$ and $P_{c}$ and subsequent calculating the $\beta$ and $\tau$, we can write

$$
f_{m}=(1-P)\left(\beta+\frac{\tau_{0}}{P_{n}}\right),
$$

where $\beta$ and $\tau_{0}$ are friction characteristics depending on the friction conditions.

Friction characteristics $\beta$ and $\tau_{0}$ were calculated for each value of porosity, varying only the $P_{n}$, and then by the least squares method we found expressions for $\beta$ and $\tau_{0}$ from $P$ :

$$
\begin{gathered}
\beta(P)=0.00677+0.0103 \cdot P-0.000394 \cdot P^{2}, \\
\tau_{0}(P)=0.05(5)+0.000532 \cdot P^{2}-0.0000267 \cdot P^{3} .
\end{gathered}
$$

The number of regression equations members and their significance was determined by minimizing the residual variance $S_{\text {ost }}[60]$, the model adequacy was tested by the Fisher criterion $F$.

For the significance level 0.25 , that is, the probability that the hypothesis can be rejected, the tabulated value of $F$ is 2.0. The values of $F$, equal to 2.3 and 7.7 , calculated from expressions (13) and (14), respectively, exceeded tabular values, therefore, the equations are adequate.

Behavior of stressed porous materials has some special features [61]. Firstly, the pores reduce the range of physical and mechanical properties of the material, and secondly, pores are obstacles for dislocation motion and crack growth.

Assuming that the separation of the wear particles is due to crack formation and its subsequent growth, and as the pore was examined as an obstacle for the crack movement which is similar to the dislocation movement, so stress can be calculated by the formula [48]:

$$
\tau_{m}=\frac{a \cdot G \cdot B}{R},
$$

where $\tau_{m}$-crack movement stress in porous material; $a \approx$ 1 -coefficient; $G$-shear modulus; $B$-Burgers vector; $R$ the distance between the pores. $\tau_{m}$ does not act on the entire area, but only in places of contact. The bearing surface curve is usually given with $t_{p}-\varepsilon$ coordinates. On the basis of theoretical researches, Kragelskii and Demkin proved that the Kragelskii-Demkin equation can be used for the top of the bearing surface curve [59]:

$$
t_{p}=b \cdot \varepsilon^{\nu},
$$

where $t_{p}$-relative contact area; $b$ and $\nu$ are bearing surface curve parameters; $\varepsilon$-relative approach.

The bearing surface curve parameters $b=3.5$ and $v=$ 1.8 were taken from [59]. Kragelskii and Mihin established during theoretical and empirical studies that real field of contact is proportional to applied load and doesn't depend on roughness of the surface (during a plastic contact). It terms of it relative approach can be determined with the formula [59]:

$$
\varepsilon=\left(\frac{\alpha_{1} \cdot C 1 \cdot P_{n}}{b \cdot \mathrm{HB}}\right)^{1 / v},
$$

where $\alpha_{1}$-the coefficient depending on the type of contact (it varies from 0.5 to 1 ) $\alpha_{1} \approx 0.75 ; C 1$-the constant that relates the contour and nominal pressure.

Since the relation of tensions acting on contour area $\left(\tau_{m}\right.$. $\left.t_{p}\right)$ to contour pressure $P_{c}$ is analogous to a corresponded forces relation [62], so dependence of inhibition of the crack in the pores on the friction ratio can be determined from the expression:

$$
\Delta f=\frac{\tau_{m}}{C 1 \cdot P_{c}} \cdot t_{p},
$$

where $\tau_{m}$-stress; $\Delta f$-friction ratio change. Therefore, the approximation value of $f_{m}$ was carried out further in view of $\Delta f$. Accounting of the possibility of crack inhibition by 
TABLE 3: Iron powder wear characteristics.

\begin{tabular}{|c|c|c|c|c|c|c|c|}
\hline \multirow{2}{*}{$P, \%$} & \multirow{2}{*}{$f$} & \multirow{2}{*}{$f-f_{d}$} & \multirow{2}{*}{$\Delta f$} & \multirow{2}{*}{$P^{-1}, \mathrm{MPa}^{-1}$} & \multicolumn{2}{|c|}{$f_{m}$} & \multirow{2}{*}{$\mathrm{HB}$} \\
\hline & & & & & Experimental & Calculated (12) & \\
\hline \multirow{5}{*}{2} & 0.22 & 0.145 & 0.036 & 2.80 & 0.148 & 0.172 & \multirow{5}{*}{101} \\
\hline & 0.19 & 0.096 & 0.024 & 1.10 & 0.098 & 0.083 & \\
\hline & 0.15 & 0.023 & 0.026 & 0.34 & 0.023 & 0.044 & \\
\hline & 0.33 & 0.261 & 0.023 & 4.20 & 0.272 & 0.283 & \\
\hline & 0.26 & 0.173 & 0.022 & 1.70 & 0.180 & 0.120 & \\
\hline \multirow{4}{*}{4} & 0.21 & 0.112 & 0.020 & 1.00 & 0.117 & 0.087 & \multirow{4}{*}{95} \\
\hline & 0.17 & 0.053 & 0.013 & 0.50 & 0.055 & 0.063 & \\
\hline & 0.16 & 0.030 & 0.017 & 0.33 & 0.031 & 0.050 & \\
\hline & 0.22 & 0.141 & 0.058 & 3.00 & 0.154 & 0.150 & \\
\hline \multirow{4}{*}{8.6} & 0.17 & 0.105 & 0.052 & 1.20 & 0.096 & 0.100 & \multirow{4}{*}{76} \\
\hline & 0.18 & 0.067 & 0.047 & 0.71 & 0.073 & 0.082 & \\
\hline & 0.17 & 0.072 & 0.043 & 0.36 & 0.070 & 0.071 & \\
\hline & 0.22 & 0.146 & 0.065 & 4.0 & 0.169 & 0.148 & \\
\hline \multirow{3}{*}{13.6} & 0.17 & 0.117 & 0.056 & 1.6 & 0.116 & 0.097 & \multirow{3}{*}{75} \\
\hline & 0.20 & 0.074 & 0.056 & 0.94 & 0.086 & 0.090 & \\
\hline & 0.22 & 0.13 & 0.10 & 2.80 & 0.163 & 0.170 & \\
\hline \multirow{2}{*}{20} & 0.17 & 0.056 & 0.089 & 1.10 & 0.07 & 0.093 & \multirow{2}{*}{48} \\
\hline & 0.17 & 0.04 & 0.083 & 0.65 & 0.05 & 0.073 & \\
\hline
\end{tabular}

Note: $\Delta=3.5 \cdot 10^{-2}$.

pores does not improve the approximation [62], as such mechanism can operate only when the crack path to fracture, significantly longer than the distance between the pores.

In the experiment discussed, the composition of wear particles corresponded to $\mathrm{Fe}_{2} \mathrm{O}_{3}$. Their size (see Figure 7) was much smaller than the distance between the pores, so a necessary condition for crack inhibition by pores (crack blunting) was not satisfied.

However, the increased size of pores at $P \approx 4 \%$ corresponds to the largest value of $f$, which indicates a relationship between the inhibition of dislocation motion and crack growth. Regardless of the mechanism by which the dislocation overcomes obstacle, stress is always inversely proportional to $R$ [48].

The growth of pore size and the elongation of the distance between pores relieve the deformation in the active area, and it leads to growth of the plastically deformed contacts portion and the friction ratio. According to [63] the transition from elastic to plastic contact leads to a greater dependence of $f_{d}$ on $P_{c}$ and $\Delta$ (in the case of elastic contact $f_{d} \sim p_{c}^{0.2} \cdot \Delta^{0.4}$, and plastic contact $f \sim p_{c}^{0.25} \cdot \Delta^{0.25}$, as to an increasing of $f_{m}$ (in the case of elastic contact $\left(f_{m}-\beta\right) \sim$ $p_{c}^{-0.2} \cdot \Delta^{-0.4}$, and plastic contact $\left(f_{m}-\beta\right) \sim \mathrm{HB}^{-1}$. Therefore, the most probable cause of the local extremum of the friction ratio dependence on the porosity is increased size of pores at $P \approx 4 \%$. An indirect confirmation of this assumption is the reduction of the difference between the maximum and average values of $f$ with contour pressure increasing (i.e., an increasing of the proportion of plastic contact).

Features of porous materials $[55,64,65]$ allow us to relate the friction surface characteristics and the material structure with wear resistance, Table 4, Figure 9.

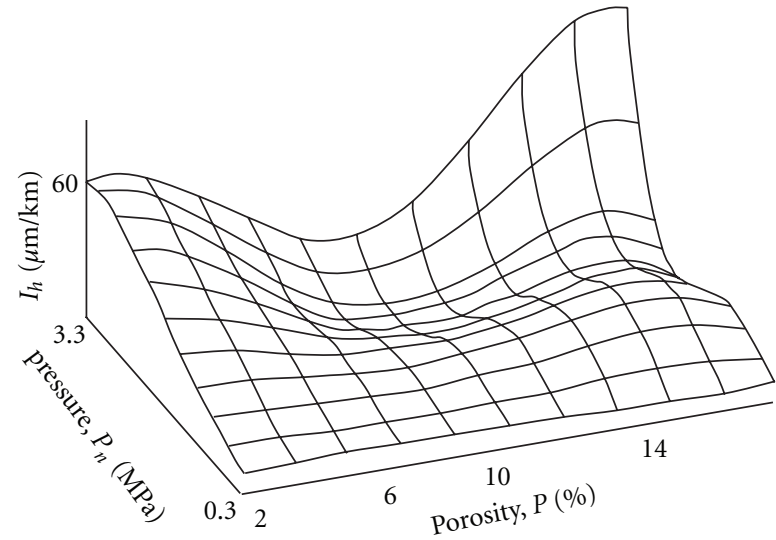

Figure 9: Response surface of $I\left(P, P_{n}\right)$.

Iron wear during dry friction on steel is a fatigue wear $[66,67]$.

At a certain stage of the interaction surface reaches steady state characterized by a constant dislocation cluster density in the slip bands; lattice parameters deflection and of dislocation density at a depth of $10-15 \mathrm{~mm}$ remains constant $[64,67]$.

Thus, there are the necessary prerequisites for interpreting experimental results involving the major tenets of the theory of fatigue wear. Specific linear wear rate $\left(i_{h}\right)$ was got in assumption of fatigue character of the wear. This assumption was based on material volume worn for one action, which is proportional to deformed volume and is inversely proportional to a number of acts leading to metal 
TABLE 4: Iron powder characteristics.

\begin{tabular}{|c|c|c|c|c|c|c|c|}
\hline \multirow{2}{*}{$P, \%$} & \multicolumn{2}{|c|}{$I_{h}$, microns $/ \mathrm{km}$} & \multirow{2}{*}{$P, \mathrm{MPa}$} & \multirow{2}{*}{$K_{\mathrm{IC}}, \mathrm{MPa} \cdot \mathrm{m}^{1 / 2}$} & \multirow{2}{*}{$\mu$} & \multirow{2}{*}{$d \cdot 10^{6}, \mathrm{~m}$} & \multirow{2}{*}{$\mathrm{HB}$} \\
\hline & Experimental & Calculated (27) & & & & & \\
\hline \multirow{4}{*}{2} & 6.2 & 3.8 & 0.35 & \multirow{4}{*}{32.0} & \multirow{4}{*}{0.28} & \multirow{4}{*}{1.14} & \multirow{4}{*}{101} \\
\hline & 9.3 & 12.2 & 0.89 & & & & \\
\hline & 24.0 & 23.7 & 1.49 & & & & \\
\hline & 66.8 & 57.6 & 2.95 & & & & \\
\hline \multirow{5}{*}{4} & 3.7 & 2.5 & 0.24 & \multirow{5}{*}{24.6} & \multirow{5}{*}{0.28} & \multirow{5}{*}{2.02} & \multirow{5}{*}{95} \\
\hline & 7.0 & 8.1 & 0.60 & & & & \\
\hline & 18.6 & 15.6 & 1.00 & & & & \\
\hline & 40.9 & 38.0 & - & & & & \\
\hline & 60.4 & 63.9 & 2.00 & & & & \\
\hline \multirow{5}{*}{8.6} & 4.6 & 3.5 & 0.33 & \multirow{5}{*}{18} & \multirow{5}{*}{0.27} & \multirow{5}{*}{1.78} & \multirow{5}{*}{76} \\
\hline & 10.6 & 11.4 & 0.83 & & & & \\
\hline & 20.0 & - & 1.40 & & & & \\
\hline & 23.3 & 22.2 & 2.80 & & & & \\
\hline & 69.8 & 90.8 & 4.20 & & & & \\
\hline \multirow{4}{*}{13.6} & 4.3 & 3.7 & 0.25 & \multirow{4}{*}{17} & \multirow{4}{*}{0.26} & \multirow{4}{*}{1.79} & \multirow{4}{*}{75} \\
\hline & 11.2 & 9.0 & 0.64 & & & & \\
\hline & 23.2 & 17.1 & 1.06 & & & & \\
\hline & 4.6 & 3.7 & 0.36 & & & & \\
\hline \multirow{3}{*}{20} & 16.3 & 11.9 & 0.90 & \multirow[t]{3}{*}{8} & \multirow[t]{3}{*}{0.25} & \multirow[t]{3}{*}{1.83} & \multirow[t]{3}{*}{48} \\
\hline & 21.1 & 22.9 & 1.50 & & & & \\
\hline & 62.6 & 57.8 & 3.10 & & & & \\
\hline
\end{tabular}

fracture [63]:

$$
i_{h}=\frac{\sqrt{v / 4}}{2(v+1) n_{k r}} \cdot \sqrt{h / R_{c v}},
$$

where $h$-the rapprochement between the friction surfaces; $R_{c v}=77$ microns [68] - the radius of curvature; $n_{k r}$ - the number of cycles, leading to the fracture.

Integral linear wear rate $I_{h}$, and specific $i_{h}$ wear rate are related by [69]:

$$
I_{h} \approx i_{h} \cdot t_{p} \approx \frac{\sqrt{v / 4}}{2(v+1) n_{k r}} \cdot \sqrt{h / R_{c v}} \cdot t_{p} .
$$

Rapprochement between the two surfaces when the unsaturated plastic contact takes place [59]:

$$
h=\varepsilon \cdot R_{\max }=\left(\frac{\alpha \cdot P_{c}}{b \cdot \mathrm{HB}}\right)^{1 / v} \cdot R_{\max }
$$

where $R_{\max }$-the greatest distance between the bumps and hollows within the gauge length.

Solving (19)-(21), we obtain the basic equation of wear

$$
I_{h}=\frac{0.0156}{n_{k r}} \cdot\left(\frac{P_{c}}{\mathrm{HB}}\right)^{1.28} .
$$

Fatigue wear theory assumes localized damage in a small volume. As follows from the fracture mechanics, the separation of particles occurs when the stress concentration reaches the critical value $K_{\mathrm{IC}}$.

This magnitude of stress concentration corresponds to a critical crack length $l_{c}$. Dependence of stress intensity factor $\Delta K$ with the crack propagation rate $d l / d N$ in case of endurance fracture determined by Paris formula:

$$
\frac{d l}{d N}=A(\Delta K)^{n},
$$

where $N$-number of cycles; $A$ and $n$-coefficients. Fatigue crack growth studies have shown that the coefficient $A$ depending on the strain hardening varies from $1.16 \cdot 10^{-5}$ to $6.77 \cdot 10^{-7} ; n$ exponent reduces from 4.0 (for the degree of cold deformation of 50\%) to 2.88 (at baseline) [70].

The stress intensity on the crack top determines stress intensity factor $K$ which is a tension and crack length $l$ function. For short cracks $\left(l / a_{r}<0.03, a_{r}\right.$-contact pad radius) it is written in the paper [53] like

$$
K=2 \sigma_{y} \sqrt{l},
$$

where $\sigma_{y}$-fracture stress; $l$-crack length. In the case of Hertz contact at the contact area interface [53]:

$$
\sigma_{y}=\frac{1-2 \mu}{2} \cdot P_{c} .
$$

The contact between the friction surfaces is carried out only in the microroughnesses contact plane. In this case, a critical crack length which is corresponded to a critical volume of stress intensity factor $K_{\mathrm{IC}}$, the real contact area is counted by introducing $t_{p}$ taking into account (16), (17), (24), and (25) can be written like

$$
l=\left[\frac{K_{\mathrm{IC}} \cdot t_{p}}{(1-2 \mu) \cdot P_{c}}\right]^{2}=\left[\frac{0.75 \cdot K_{\mathrm{IC}}}{\mathrm{HB}(1-2 \mu)}\right]^{2} .
$$


For the initial size of the defect, by analogy with [56] a half the diameter of the pores $\left(l_{0}=d / 2\right)$ was taken. The values of $d, K_{\mathrm{IC}}$, and $\mu$ were taken from [70].

The deformed volume fracture occurs when $\Delta K$ reaches a value $K_{\mathrm{IC}}$, which corresponds to the critical defect size $l$ and the value of $N=n_{k r}$. Solving expressions (22), (23), (26), and assuming a linear relationship between $P_{n}$ and $P_{c}$, we have a formula to determine the wear rate.

Fracture of the deformable volume happens when $\Delta K$ reaches $K_{\mathrm{IC}}$ value that is corresponded to a critical defect size $l$ and $N=n_{k p}$ value. Substituting (23), (26) in (22) and ignoring the equation got on conditions that half of the pore diameter was taken as an initial defect size $\left(l_{0}=d / 2\right)$, on the analogy of paper [56] implying linear connection between $P_{n}$ and $P_{c}$, a formula for wear intensity was gotten

$$
\begin{aligned}
& I_{h} \\
& =\frac{0.156 \cdot\left(P_{n} / \mathrm{HB}\right)^{0.128} \cdot(n / 2-1) \cdot A[(1-2 \mu) \mathrm{HB} / 0.75]^{n}}{(d / 2)^{(1-n / 2)}-\left(0.75 K_{\mathrm{IC}} /(1-2 \mu) \mathrm{HB}\right)^{(2-n)}},
\end{aligned}
$$

where $d$ - the average pore diameter.

$K_{\mathrm{IC}}, d$, and $\mu$ values were taken from paper [70]. Thus linear intensity of wear is determined by load, hardness, crack growth resistance, structure characteristic element size-pore size, Poisson ratio, and fatigue fracture parameters.

Fitting the experimental data by expression (27), the values of $A=1.38 \cdot 10^{-7}$ and $n=2.11$ were determined. As seen from Figure 9, the function $I_{h}(P)$ is nonmonotonic over the entire range of variation of $P_{n}$. A similar result for the constant values of pressure and a wide range of $P$ was experimentally obtained in [55]. Good agreement between the values of the coefficients $A$ and $n$ with the published data [71] and a satisfactory approximation of the experimental results confirm the correctness of the approach adopted for the study of porous iron.

\section{Lubricated Friction and Wear Processes}

Boundary friction conditions of powder materials are typical for most parts functioning. This mode is performed during startup and shutdown, even if the products are designed for operation in a hydrodynamic lubrication [72]. The tests differed only in that the oil in the friction zone was fed through a rotating counterbody dipping into the bowl with the lubricant, Table 5.

Tables 4 and 5 show that for identical values of porosity and pressure the friction ratio value decreases several times with lubrication. It changes the dependence of $f$ on the pressure. Under dry friction an increase in pressure leads to a decrease in the $f$ value, but under lubricated friction pressure increasing results in $f$ increase. This form of the function $f(P)$ can be explained as follows. During elastic unsaturated contact friction ratio dependence on major friction unit characteristics $\tau_{0}$ and $\beta$, mechanical features of less hard material of friction pair $(\mu, E)$, contour pressure and roughness of harder element of friction pair $(\Delta)$ according to [63] looks like

$$
f=\frac{2.4 \tau_{0}\left(1-\mu^{2} / E\right)^{4 / 5}}{P_{c}^{1 / 5} \cdot \Delta^{2 / 5}}+\beta+0.23 \alpha_{g} P_{c}^{1 / 5} \Delta^{2 / 5}\left(\frac{\left(1-\mu^{2}\right)}{E}\right)^{1 / 5},
$$

where $\alpha_{g}$-coefficient of hysteresis losses under friction.

Equation for elastic unsaturated contact has the same structure and is different only in indexes $P_{c}$ and $\Delta, \mu, E$ and constants values.

The presence of lubricating film dramatically reduces the frictional bond shear strength $\tau_{0}$, and hence the contribution of the first term of (28). Deformation component of the friction ratio is proportional to the contour pressure with a small exponent, as it observed experimentally. Features were observed only when $P=8.6 \%$ (a transition from open to closed porosity occurs), and when $P=4 \%$ (a local extremum of the pore size detected) [70]. The porous structure affects the surface deformation in the active area [56], so that the greatest value of the friction ratio is connected with the extreme size of the pores [62]. Low friction ratio values for high porosity samples can be explained, apparently, by the fact that in this experiment with $P>10 \%$ all porosity is open, and it facilitates the circulation of oil and heat removal from the friction surfaces. The relatively low surface temperature makes it difficult to deform and promote $f$ decreasing.

Expression (28), Table 5, correctly reflects the trends of $f(P)$. Numerical processing of experimental data have not performed as well as the ranges of the friction ratio for most porosity values are small and the accuracy of $f$ at low pressures, comparable with the difference between the test results.

The thickness of oil layer was estimated according to the equation [72] which is applied in case of cylinders contact:

$$
\frac{h}{R_{c v}}=1.65\left(\frac{\left(V_{1}+V_{2}\right) \cdot \alpha_{p} \cdot V}{2 R_{n}}\right)^{0,73} \cdot\left(\frac{P_{n}}{E /\left(1-\mu^{2}\right)}\right)^{-0.18},
$$

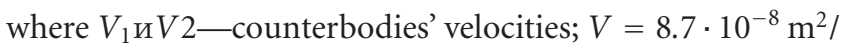
$\mathrm{kg}$ —oil dynamic viscosity; $\alpha_{p}=4.1 \cdot 10^{-3} \mathrm{~kg} \cdot \mathrm{s} / \mathrm{m}^{2}$ —oil piezocoefficient; $R_{n}$-reduced radius of curvature.

Calculations showed that the porosity has a little influence on the oil layer thickness (Figure 10), which probably explains the weak dependence of the friction ratio on $P$ at low pressures.

The expression (29) tested with the pressure transducer DD-10 as follows. The sample was set and lap it dry. The sensor readings were calibrated, depending on the bias. Under dry friction the sensor readings were recorded and then counterbody was dipped into the oil. At a pressure of $0.25 \mathrm{MPa}$ the rapprochement $h$ changed to $1.0-1.5$ microns; this agrees well with Figure 10. At higher pressures (about $1 \mathrm{MPa}$ ) the accuracy of determining the change in approach is close to the calculated value of the oil film, at a pressure below $0.25 \mathrm{MPa}$ tests were not carried out due to specific means for setting the sample.

The microhardness of the structural components of the friction surface was from 120 to $450 \mathrm{HV}_{0.05}$ (areas with 
TABLE 5: Antifriction properties of iron under limited lubrication.

\begin{tabular}{|c|c|c|c|c|c|c|}
\hline \multirow{2}{*}{$P, \%$} & \multirow{2}{*}{ Hardness, $\mathrm{MPa}$} & \multirow{2}{*}{$P, \mathrm{MPa}$} & \multirow{2}{*}{$f$} & \multicolumn{2}{|c|}{$I_{h}$, microns $/ \mathrm{km}$} & \multirow{2}{*}{$d \cdot 10^{6}, \mathrm{~m}$} \\
\hline & & & & Experimental & Calculated (39) & \\
\hline \multirow{5}{*}{2} & \multirow{5}{*}{1010} & 0.35 & 0.05 & 0.6 & 1.3 & \multirow{5}{*}{1.14} \\
\hline & & 0.89 & 0.05 & 0.9 & 1.6 & \\
\hline & & 1.5 & 0.07 & 1.6 & 2.1 & \\
\hline & & 3.0 & 0.07 & 2.9 & 2.8 & \\
\hline & & 4.5 & 0.07 & 3.3 & 3.4 & \\
\hline \multirow{5}{*}{4} & \multirow{5}{*}{950} & 0.24 & 0.05 & 1.7 & 1.4 & \multirow{5}{*}{2.02} \\
\hline & & 0.60 & 0.05 & 2.3 & 1.7 & \\
\hline & & 1.0 & 0.09 & 2.9 & 1.9 & \\
\hline & & 2.0 & 0.12 & 3.5 & 2.5 & \\
\hline & & 3.0 & 0.12 & 3.7 & 3.0 & \\
\hline \multirow{5}{*}{5.9} & \multirow{5}{*}{860} & 0.33 & 0.05 & 0.9 & 1.3 & \multirow{5}{*}{1.36} \\
\hline & & 0.83 & 0.05 & 1.4 & 1.7 & \\
\hline & & 1.4 & 0.06 & 2.0 & 2.0 & \\
\hline & & 2.8 & 0.06 & 2.3 & 2.7 & \\
\hline & & 4.2 & 0.06 & 4.0 & 3.3 & \\
\hline \multirow{5}{*}{8.6} & \multirow{5}{*}{760} & 0.33 & 0.05 & 1.3 & $1.5 / 0.76$ & \multirow{5}{*}{1.78} \\
\hline & & 0.83 & 0.05 & 1.6 & $1.7 / 1.2$ & \\
\hline & & 1.4 & 0.09 & 1.8 & $2.0 / 1.5$ & \\
\hline & & 2.8 & 0.09 & 2.3 & $2.7 / 2.1$ & \\
\hline & & 4.2 & 0.12 & 3.1 & $3.5 / 2.5$ & \\
\hline \multirow{5}{*}{13.6} & \multirow{5}{*}{750} & 0.25 & 0.04 & 0.84 & 0.88 & \multirow{5}{*}{1.79} \\
\hline & & 0.64 & 0.04 & 1.0 & 1.0 & \\
\hline & & 1.06 & 0.06 & 1.6 & 1.3 & \\
\hline & & 2.12 & 0.06 & 1.7 & 1.3 & \\
\hline & & 3.18 & 0.07 & 3.5 & 2.2 & \\
\hline \multirow{5}{*}{20} & \multirow{5}{*}{480} & 0.36 & 0.05 & 0.87 & 1.0 & \multirow{5}{*}{1.83} \\
\hline & & 0.90 & 0.05 & 1.7 & 1.6 & \\
\hline & & 1.5 & 0.06 & 2.9 & 2.0 & \\
\hline & & 3.0 & 0.06 & 3.1 & 2.9 & \\
\hline & & 4.5 & 0.06 & 3.3 & 3.4 & \\
\hline
\end{tabular}

high hardness ( $\left.1000 \mathrm{HV}_{0.05}\right)$ was not enough). According to the microhardness studies regardless of porosity, the basic structural components were sorbite and troostite.

X-ray analysis showed an increase in lattice parameter with respect to the standard on $0.03-0.06 \%$ for all samples. This confirmed the assumption about the carbon saturation of the thin surface layers under friction of iron with limited lubrication.

Thus, boundary friction could result in contact surfaces heating above the temperatures of phase transformations and the carburizing of iron. Similar results for the steels are presented in [73].

As the friction ratio, wear rate is strongly related to pore size. The greatest wear $(P=4 \%)$ corresponded to the minimum value of $K_{\mathrm{I} C}$. This indicates a relationship between pore size (pore size is greatest when $P=4 \%$ ), fracture toughness, and wear resistance.

Since the active layer thickness significantly exceeds the thickness of the oxide products of wear and the size and the depth of diffusion penetration of interstitial elements, physical and mechanical properties of the material have an effect on wear resistance. Currently accepted methodology for assessing the wear rate based on the determination of physical and mechanical properties $[63,74]$, but have a low accuracy of prediction under lubricated friction [74], are sufficient for engineering calculations.

Linear wear rate can be determined from the expression [59]:

$$
I_{h}=\frac{\sqrt{\nu / 4}}{2(\nu+1) n_{k r}} \cdot \sqrt{h / R_{c v}} \cdot b \cdot \varepsilon^{\nu}
$$

Regardless of the contact type:

$$
\varepsilon=\frac{h}{R_{\max }}
$$

The film thickness, Figure 10, under the boundary friction was comparable to the rapprochement between the two surfaces, and therefore elastic contact took place. 


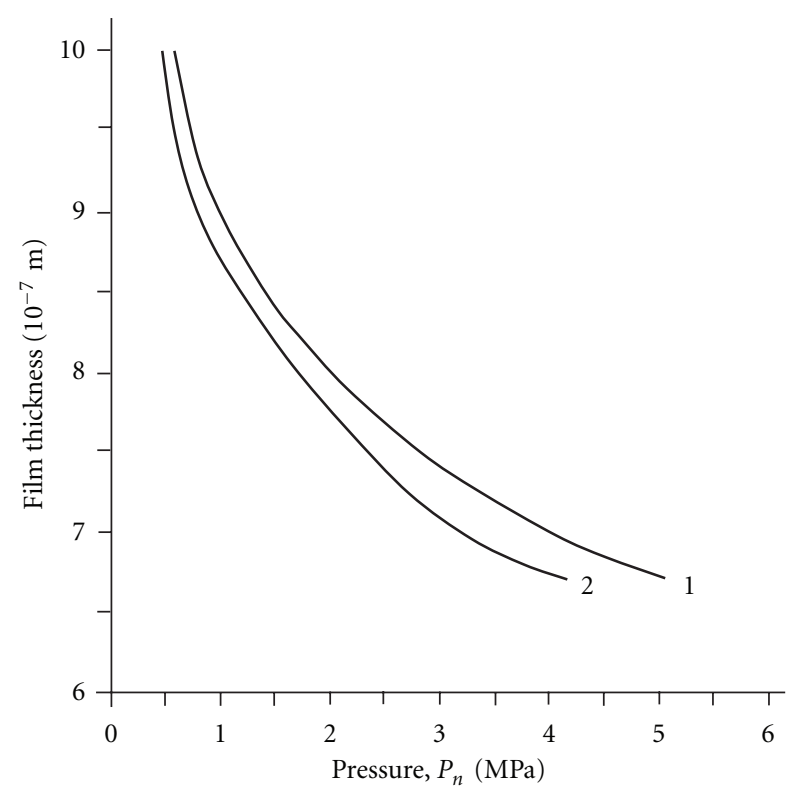

FIGURE 10: Dependence of the thickness $h$ of the oil film on the pressure: $1-P=2 \%, 2-P=20 \%$.

Within the contour area under elastic unsaturated contact, the rapprochement was calculated as [59]:

$$
h=\left(\frac{5 P_{c} R^{1 / 2}\left(1-\mu^{2}\right) R_{\max }^{\nu}}{b \nu(\nu-1) K_{1} E}\right)^{2 /(2 v+1)} .
$$

The coefficient $K_{1}=0.5$ was determined from nomograms [59]. The relative rapprochement under saturated contact was assessed according to the expression [59]:

$$
\mathcal{E}=\frac{1}{(b v)^{1 /(\nu-1)}}
$$

In case of elastic unsaturated contact (34) for linear wear rate $I_{h}$ is got after substitution of (31), (32), (33) in (30).

$$
I_{h}=\frac{\sqrt{v / 4}}{2(\nu+1) n_{k r}} \cdot \sqrt{\frac{R_{\max }}{(b \nu)^{1 /(v-1)} \cdot R_{c v}}} \cdot b \cdot\left(\frac{1}{(b v)^{1 /(v-1)}}\right)^{\nu} .
$$

In case of elastic unsaturated contact, the linear wear rate $I_{h}$ can be determined on the basis of the formula (35):

$$
\begin{aligned}
I_{h}= & \frac{\sqrt{\nu / 4}}{2(\nu+1) n_{k r}} \sqrt{\left[\frac{5 P_{c} R_{c \nu}^{1 / 2}\left(1-\mu^{2}\right) R_{\max }^{v}}{b \nu(\nu-1) k_{1} E}\right]^{2 / 2 n+1}} \frac{1}{R_{c v}} \\
& \times b\left(\left[\frac{5 P_{c} R_{c v}^{1 / 2}\left(1-\mu^{2}\right) R_{\max }^{v}}{b \nu(\nu-1) K_{1} E}\right]^{2 / 2 n+1} \frac{1}{R_{\max }}\right)^{v} .
\end{aligned}
$$

The bond between $K_{\mathrm{I} C}, P_{c}$, and $l$ was found according to (36):

$$
K_{\mathrm{IC}}=\frac{(1-2 \mu) P_{\mathrm{c}} \sqrt{l}}{t_{p}}
$$

In the case of the elastic unsaturated contact, (35) and (23) were solved simultaneously, and according to (36), (37) was got. In the case of the elastic saturated contact, (34) and (23) were solved simultaneously and according to (36), (38) was got.

The values of $R_{c v}, R_{\max }, b, v$ for the porous materials were taken from [59].

In the case of unsaturated elastic contact:

$$
I_{h}=\frac{\left[P_{n}\left(1-\mu^{2}\right) / E\right]^{0.98} \cdot\left((n / 2-1) \cdot A \cdot\left(30 P_{n}^{0.565}\right)\right)^{n}}{(d / 2)^{(1-n / 2)}-\left(0.03 K_{\mathrm{IC}} / P_{n}^{0.565}\right)^{(2-n)}} \text {. }
$$

In the case of saturated elastic contact:

$$
I_{h}=\frac{0.0056(n / 2-1) \cdot A \cdot\left(10 P_{n}\right)^{n}}{(d / 2)^{(1-n / 2)}-\left(0.1 K_{\mathrm{IC}} / P_{n}\right)^{(2-n)}}
$$

The solution was found like (39) because formulas (37) and (38) are different only in exponents $P_{c}$ and in constant coefficients values, minor changes of $E$ and $\mu$ and $P_{c}$ and $P_{n}$ proportionality were also taken into account:

$$
I_{h}=\frac{a_{1} \cdot P_{n}^{n_{1}}(n / 2-1)}{(d / 2)^{(1-n / 2)}-\left(C 3 \cdot K_{\mathrm{IC}} / P_{n}^{n_{2}}\right)^{(2-n)}} .
$$

In the area of $P=8-10 \%$, the transition from closed to open porosity occurred, so the experimental data (see Table 5) was approximated separately for $P$ from 2 to $8.6 \%$ (numerator) and from 20 to $8.6 \%$ (denominator). In the first case, $a_{1}=76.2, C 3=0.03, n_{1}=0.66, n_{2}=3.77$, and $n=$ 2.32 ; in the second $a_{1}=36.3, C 3=6.5, n_{1}=0.086, n_{2}=$ 1.37, and $n=1.67$.

Note that $n$ varies from 2 to 8 under fatigue fracture, prestrain and impurity content increase caused $n$ increase. Among other factors, the value of $n$ depends on the pressure and cycle asymmetry.

In $[73,75]$ similar values of $n$ for cold-plastic steel at high cycle asymmetry are represented. Apparently, $m$ changing from 2.32 to 1.67 caused by pores changes. Closed porosity makes it difficult to circulate the oil, and therefore the main influence has reduced the concentration of stress. In case of open porosity, pores provide constant oil circulation and heat dissipation from the friction surfaces, so the value of $n<2$.

In general, dependence (39) describes the experiment with sufficient accuracy for engineering calculations; the number of undetermined coefficients is much smaller than in techniques used nowadays $[63,74]$.

The iron powder tribological characteristics study revealed the following patterns of relationship. Under dry friction the friction ratio $f$ and wear rate $I_{h}$ were changed nonmonotonic with increasing porosity. The reason for the nonmonotonic dependence of $f(P)$ is in pore size and distance between them changes, that determine the deformation in the active area. Depending on the elastic and plastic deformed contacts portion, the type of contact is established, and it determines the friction ratio value, along with the physical and mechanical characteristics of the material. The surface fracture of iron powder at few $\mathrm{MPa}$ 
pressure is the nature of fatigue. The symbasis of $I_{h}(P)$ and $K_{\mathrm{IC}}(P)$ dependences is determined by the contact surface fracture localization in a small volume, and the material separation occurs only when the critical value of stress concentration is reached.

Limited lubricated friction under the same pressures provides elastic contact and very little shear strength of frictional bond. The surface of the porous iron is saturated with carbon. The porosity of $8-10 \%$ (carbonyl iron) provides a transition from the closed to open porosity, which naturally affects the value of the friction ratio and wear rate.

As in the case of dry friction in boundary friction, $f(P)$ and $I_{h}(P)$ functions are nonmonotonic. With sufficient accuracy for engineering calculations the wear rate under boundary friction can be calculated on the assumption of elastic contact.

The developed model predicted the values of fracture toughness, friction ratio, and integral linear wear rate of porous steel and bronze [74-84].

\section{Conclusion}

Pores' structure changes during the consolidation process, that provides blunting and bend of the crack while moving between pores, is the reason for non-monotonic dependence $K_{\mathrm{IC}}(P)$. During the dry sliding and during the boundary friction $f(P)$ ИI $I_{h}(P)$ functions are nonmonotonic. Local $f(P)$ and $I_{h}(P)$ extremum appearance is caused by different reasons (pore sizes and structure penetrability), but is mainly the consequence of pore structure transformation.

\section{List of Symbols}

$K_{\mathrm{IC}}:$ Fracture toughness, $\mathrm{MN} / \mathrm{m}^{3 / 2}$

$K_{Q}$ : Estimated fracture toughness, $\mathrm{MN} / \mathrm{m}^{3 / 2}$

$P$ : $\quad$ Porosity, \%

$\sigma_{0.2}$ : Yield strength, $\mathrm{MPa}$

$g$ : Crack distribution energy

T: Linear crack front tension, $\mathrm{N}$

E: Elastic modulus, MPa

$\mu$ : Poisson's ratio

A: Specific energy of uniform deformation

$\gamma_{\text {eff: }}$ Effective surface energy of the

Griffiths-Orowan theory

$l_{d}$ : Length dimension constant

$\delta_{e}$ : Uniform Deformation, \%

$\sigma_{B}:$ Tensile Strength, MPa

$\tau$ : $\quad$ Crack movement stress, $\mathrm{MPa}$

$r$ : Pore radius, $\mathrm{m}$

$\Gamma: \quad$ Interface energy, $\mathrm{J} / \mathrm{m}^{2}$

$b_{0}$ : Interatomic distance, $\mathrm{m}$

$\Omega: \quad$ Distance between the inhomogeneities (pores), $\mathrm{m}$

$f:$ Friction ratio

$P_{n}$ : Nominal pressure, $\mathrm{MPa}$

$P_{c}$ : Contour pressure, $\mathrm{MPa}$

$f_{d}$ : Friction ratio deformation component
$\Delta: \quad$ Microroughnesses characteristic of a rigid material of the friction pair

HB: Hardness

$f_{m}: \quad$ Molecular component of friction ratio

Ra: $\quad$ Arithmetic mean deviation of profile, $\mathrm{m}$

$\beta$ and $\tau_{0}$ : Friction characteristics

$S_{\text {ost }}$ : Residual variance

$F: \quad$ Fisher criterion

$\tau_{m}: \quad$ Crack movement stress in porous material, $\mathrm{MPa}$

a: $\quad$ Coefficient

G: $\quad$ Shear modulus, $\mathrm{MPa}$

$B: \quad$ Burgers vector, $\mathrm{m}$

$R: \quad$ Distance between the pores, $\mathrm{m}$

$b$ and $v$ : Bearing surface curve parameters

$\varepsilon: \quad$ Relative approach

$t_{p}: \quad$ Relative contact area

$\alpha_{1}$ : The coefficient depending on the type of contact

C1: The constant that relates the contour and nominal pressure

$\Delta f: \quad$ Friction ratio change

$i_{h}$ : $\quad$ Specific linear wear rate

$h$ : $\quad$ Rapprochement between the friction surfaces, $\mathrm{m}$

$R_{c v}: \quad$ Radius of curvature

$n_{k r}: \quad$ Number of cycles, leading to the fracture

$I_{h}: \quad$ Integral linear wear rate

$R_{\max }: \quad$ The greatest distance between the bumps and hollows within the gauge length

$\Delta K: \quad$ Stress intensity factor change (Paris formula), $\mathrm{MN} / \mathrm{m}^{3 / 2}$

$N: \quad$ Number of cycles (Paris formula)

$A$ and $n$ : Coefficients (Paris formula)

$K: \quad$ Stress intensity factor, $\mathrm{MN} / \mathrm{m}^{3 / 2}$

$l: \quad$ Crack length, $m$

$a_{r}: \quad$ Radius of contact area, $\mathrm{m}$

$\sigma_{y}: \quad$ Fracture stress, $\mathrm{MPa}$

$d$ : $\quad$ Average pore diameter, $\mathrm{m}$

$\alpha_{g}: \quad$ Coefficient of hysteresis losses under friction

$V_{1}$ и $V_{2}$ : Counterbodies' velocities, $\mathrm{m} / \mathrm{s}$

$V: \quad$ Oil dynamic viscosity, $\mathrm{m}^{2} / \mathrm{kg}$

$\alpha_{p}: \quad$ Oil piezocoefficient, $\mathrm{kg} \cdot \mathrm{s} / \mathrm{m}^{2}$

$R_{n}: \quad$ Reduced radius of curvature, $\mathrm{m}$

$K_{1}$ : Coefficient

C3: $\quad$ Coefficient.

\section{References}

[1] H. P. Dzhoy, "The past and the future of tribology," Journal of Friction and Wear, vol. 11, no. 1, pp. 149-159, 1990 (Russian).

[2] A. A. Kuklin, E. S. Michkova, and V. Y. Bulanov, Technology and Economics of Powder Metallurgy, Nauka, Moscow, Russia, 1989.

[3] H. Danninger, C. Gierl, G. Mühlbauer, M. S. Gonzalez, J. Schmidt, and E. Specht, "Thermophysical properties of sintered steels: effect of porosity," International Journal of Powder Metallurgy, vol. 47, no. 3, pp. 31-41, 2011.

[4] C. Sohar, A. Betzwar-Kotas, C. Gierl, H. Danninger, and B. Weiss, "Gigacycle fatigue response of tool steels produced by powder metallurgy compared to ingot metallurgy tool steels," International Journal of Materials Research, vol. 101, no. 9, pp. 1140-1150, 2010. 
[5] M. Dlapka, H. Danninger, C. Gierl, and B. Lindqvist, "Defining the pores in PM components," Metal Powder Report, vol. 65 , no. 2 , pp. 30-33, 2010.

[6] H. Winkelmann, M. Varga, E. Badisch, and H. Danninger, "Wear mechanisms at high temperatures. Part 2: temperature effect on wear mechanisms in the erosion test," Tribology Letters, vol. 34, no. 3, pp. 167-175, 2009.

[7] H. Winkelmann, E. Badisch, M. Kirchgaßner, and H. Danninger, "Wear mechanisms at high temperatures. Part 1: wear mechanisms of different Fe-based aAlloys at elevated temperatures," Tribology Letters, vol. 34, no. 3, pp. 155-166, 2009.

[8] P. Beiss and S. Lindlohr, "Porosity statistics and fayigue strength," International Journal of Powder Metallurgy, vol. 45, no. 2, pp. 39-48, 2009.

[9] P. Beiss and S. Lindlohr, "Correlation between extreme value porosity rating and fatigue strength of sintered steel," Materialpruefung/Materials Testing, vol. 50, no. 3, pp. 126-132, 2008.

[10] P. Ganesan, S Domșa, and P. Beiss, "Fracture toughness of PM alloy steels," Powder Metallurgy, vol. 48, no. 4, pp. 323-328, 2005.

[11] M. Campos, J. Sicre-Artalejo, J. J. Munoz, and J. M. Torralba, "Effect of austempering conditions on the microstructure and tensile properties of low alloyed sintered steel," Metallurgical and Materials Transactions A, vol. 41, no. 7, pp. 1847-1854, 2010.

[12] M. Campos, J. M. Torralba, C. Menapace, and A. Molinari, "Effect of copper infiltration on fracture mode in sintered steels," Powder Metallurgy, vol. 51, no. 2, pp. 176-181, 2008.

[13] R. Bidulský, M. A. Grande, and J. Bidulská, "Microstructures and fracture investigations of low alloyed vacuum treated sintered steel," Chemicke Listy, vol. 105, no. 16, pp. 506-509, 2011.

[14] R. Bidulský, M. A. Grande, and M. Kabátová, "Improved fatigue resistance of sintered steels via local hardening," Chemicke Listy, vol. 105, no. 14, pp. 159-162, 2011.

[15] M. Rosso, E. Dudrova, M. Actis Grande, and R. Bidulský, "Wear characteristics of vacuum sintered steels," Materials Science Forum, vol. 672, pp. 17-22, 2011.

[16] R. Bidulský, M. A. Grande, J. Bidulská, M. Vlado, and T. Kvačkaj, "Wear mechanism of Chromium Pre-alloyed sintered steel," High Temperature Materials and Processes, vol. 28, no. 3, pp. 175-180, 2009.

[17] R. Bidulský, M. A. Grande, J. Bidulská, and T. Kvačkaj, "Wear resistance of chromium pre-alloyed sintered steels," Materiali in Tehnologije, vol. 43, no. 6, pp. 303-308, 2009.

[18] E. Dudrova, M. Kabatova, R. Bures, R. Bidulsky, and A. S. Wronski, "Processing, microstructure and properties of 2-4\% Mn and 0.3/0.7 \% C sintered steels," Kovove Materialy, vol. 43, no. 6, pp. 404-421, 2005.

[19] S. E. Aleksandrov, A. R. Pirumov, and O. V. Chesnikova, "Plastic flow of porous materials in friction contact area," Powder Metallurgy and Metal Ceramics, vol. 47, no. 9-10, pp. 512-517, 2008.

[20] A. V. Vdovichenko, Y. N. Podrezov, and V. V. Skorokhod, "Mechanical resonance spectroscopy of interparticle boundaries in high-density iron powder compacts," Powder Metallurgy and Metal Ceramics, vol. 47, no. 5-6, pp. 366-372, 2008.

[21] A. S. Drachinskii, A. E. Kushchevskii, A. V. Perepelkin et al., "Effect of porosity on the resistance of P/M iron to cracking," Soviet Powder Metallurgy and Metal Ceramics, vol. 21, no. 12, pp. 973-977, 1982.
[22] A. G. Evans and T. G. Langdon, Structural Ceramics, Metallurgiya, Moscow, Russia, 1980.

[23] S. N. Platov, V. G. Kudryashov, M. L. Bernstein et al., "On the estimation of parameters of porous materials fracture toughness," Physicochemical Mechanics of Materials, no. 5, pp. 20-24, 1974 (Russian).

[24] L. W. Crane and R. J. Farrow, "Effect of sintering conditions on fracture toughness of a commercial alloy steel," Powder Metallurgy, vol. 23, no. 5, pp. 198-202, 1980.

[25] G. A. Klarke and R. A. Queeney, "Fracture toughness and density in sintered 316L stainless steel," The International Journal of Powder Metallurgy, vol. 8, no. 2, pp. 81-202, 1972.

[26] F. J. Esper, G. Leuze, and C. M. Sonsino, "Characteristic properties of powder metallurgical materials relevant to fatigue design," Powder Metallurgy International, vol. 13, no. 4, pp. 203-208, 1981.

[27] A. G. Zherdin, S. A. Firstov, and L. G. Bayonet, "Fracture and ductile-brittle transition in powder materials," Technological and Structural Plasticity of the Powder Materials, vol. S, pp. 8992, 1988 (Russian).

[28] J. T. Barnby, D. C. Ghosh, and K. Dinsdale, "The fractureresistance of a range of sintered steels," Powder Metallurgy, vol. 16, no. 31, pp. 55-71, 1973 (Russian).

[29] N. Ingelstrom and V. Ustimenko, "Influence of porosity and carbon content on the fracture toughness of some sintered steels," Powder Metallurgy, vol. 18, no. 36, pp. 303-322, 1975.

[30] N. Ingelstrom and H. Nordberg, "The fracture toughness of flighstrength and highductility sintereel steels," Scandina an Journal of Metallurgy, no. 4, pp. 189-192, 1975.

[31] M. Shlesar, A. Parilak, K. Pelikan et al., "Influence of porosity on the mechanical properties of sintered materials," in Proceedings of the Workshop on the Development and Use of Powder Metallurgy in Engineering, p. 17, Minsk, Belarus, 1985, Report from the Institute of Experimental Metallurgy.

[32] L. A. Zheltonoga and I. P. Gabrielov, "Characteristics of crack growth in sintered materials," Soviet Powder Metallurgy and Metal Ceramics, vol. 18, no. 10, pp. 744-748, 1979.

[33] A. S. Drachinsky, A. V. Krainov, and A. E. Kuschevsky, "The relationship with portion of intergranular fracture of iron powder," Powder Metallurgy, no. 1, pp. 43-45, 1985 (Russian).

[34] N. B. Romalis, "Calculation of effective stress intensity factors of structurally inhomogeneous bodies with cracks," Mechanics of Composite Materials, vol. 23, no. 3, pp. 287-290, 1987.

[35] G. Prefferborn, "Grundznge der fraktographie von eisenwerkstoffen," Radex Rundschan, no. 3, pp. 591-673, 1978.

[36] V. Z. Parton and E. M. Morozov, The Mechanics of Elastoplastic Fracture, Nauka, Moscow, Russia, 1974.

[37] Y. L. Krasulin, S. M. Barinov, and V. S. Ivanov, Structure and Fracture of Materials from Powders of Refractory Compounds, Nauka, Moscow, Russia, 1985.

[38] A. S. Drachinsky, Y. N. Petrov, and V. I. Trefilov, "The dislocation structure and properties of the propagation of a ductile crack in armco iron," Ukraine National Magazine, no. 13, pp. 1538-1542, 1968 (Russian).

[39] V. M. Finkel, Physical Basis of Fracture Inhibition, Metallurgiya, Moscow, Russia, 1977.

[40] D. R. Biswas, "Crack-void interaction in polycrystalline alumina," Journal of Materials Science, vol. 16, no. 9, pp. 24342438, 1981.

[41] F. F. Lang, "The interaction of a crack front with secondphcese dispersion," Philosophical Magazine, vol. 23, no. 179, pp. 983-992, 1970. 
[42] Y. I. Ragozin and Y. Y. Antonov, "Method of accelerated fracture toughness KIc testing of metallic materials," Strength of Materials, vol. 16, no. 2, pp. 179-184, 1984.

[43] V. S. Ivanova, L. R. Batvina, and L. I. Malov, "Prediction of fracture toughness and other mechanical properties, using the similarity criteria," in Fatigue and Fracture of Metals, pp. 3-35, Nauka, Moscow, Russia, 1974.

[44] W. Dhal and W. Anton, Werkstoffkunde Eisen und Stahl, Verlag Stahleisen mbH, Dusseldorf, Germany, 1983.

[45] S. V. Belov, Porous Metals in Mechanical Engineering, Mashinostroenie, Moscow, Russia, 1981.

[46] M. Balshin and S. G. Fedosov, "Contact and the elastic characteristics of copper powder ," Metals, no. 1, pp. 166-172, 1965 (Russian).

[47] K. Kreider, Ed., Composite Materials, Composites with Metal Matrix, Mashinostroenie, Moscow, Russia, 1978.

[48] R. W. Cahn, Physical Metallurgy, North-Holland, Amsterdam, The Netherlands, 1978.

[49] F. F. Lange, "The interaction of a crack front with a secondphase dispersion,” The Philosophical Magazine, vol. 22, no. 179, pp. 983-992, 1970.

[50] P. S. Theocaris and J. Milios, "Crack arrest modes of a transverse crack going through a longitudinal crack or a hole," Journal of Engineering Materials and Technology, Transactions of the ASME, vol. 103, no. 2, pp. 177-182, 1981.

[51] V. N. Antsiferov, "Features of powder material deformation with cyclic loading," Powder Metallurgy and Metal Ceramics, vol. 40, no. 11-12, pp. 569-572, 2001.

[52] A. A. Shatsov, "Mechanical properties of porous materials," Metal Science and Heat Treatment, vol. 45, no. 11-12, pp. 441444, 2003.

[53] Y. V. Kolesnikov and E. M. Morozov, Mechanics of Contact Fracture, Nauka, Moscow, Russia, 1989.

[54] I. M. Fedorchenko, A. E. Kushchevskii, V. V. Pushkarev, A. S. Drachinskii, A. V. Perepelkin, and Y. N. Podrezov, "Influence of porosity on the tribological properties of iron-base powder metallurgy materials," Soviet Powder Metallurgy and Metal Ceramics, vol. 23, no. 5, pp. 394-396, 1984.

[55] A. E. Kushchevskii, V. T. Bondar', N. A. Krylova, T. F. Mozol, and O. M. Romanenko, "An investigation of the structure of powder metallurgy iron with different porosities by scanning electron microscopy," Soviet Powder Metallurgy and Metal Ceramics, vol. 29, no. 9, pp. 745-748, 1990.

[56] V. N. Antsiferov, N. N. Maslennikov, A. A. Shatsov, and I. A. Polovnikov, "Determining the carrying capacity of powdered materials under boundary lubrication," Journal of Friction and Wear, vol. 12, no. 4, pp. 683-686, 1991 (Russian).

[57] I. I. Berkowitz and D. G. Gromakovsky, Tribology, Samara State University, Samara, Russia, 2000.

[58] GOST 23.225-99, "Ensuring durability of products. Methods of durability confirmation. General requirements" (Russian).

[59] I. V. Kragelskii and N. M. Mihin, Friction Units of Machines, Mashinostroenie, Moscow, Russia, 1984.

[60] B. A. Drozdovskii and Y. B. Friedman, The Influence of Cracks on the Mechanical Properties of Structural Steel, Metallurgizdat, Moscow, Russia, 1960.

[61] V. N. Antsiferov, N. N. Maslennikov, and A. A. Shatsov, "Strength and fracture toughness of powder steels," in Proceedings of the Universities. Iron and steel industry, no. 2, pp. 20-22, 1989.

[62] V. N. Antsiferov, N. N. Maslennikov, and A. A. Shatsov, "Effect of porosity on coefficient of friction of iron," Journal of Friction and Wear, vol. 13, no. 4, pp. 702-706, 1992 (Russian).
[63] G. Poltser and F. Meisner, Foundations of Friction and Wear, Mashinostroenie, Moscow, Russia, 1984.

[64] V. D. Zozulya, V. V. Polotay, I. A. Panfilova, and L. E. Lukin, "Effect of porosity on the plastic deformation of the surface layer at frictionsintered iron," Journal of Friction and Wear, vol. 10, no. 2, pp. 289-294, 1989 (Russian).

[65] N. G. Baranov, L. V. Zabolotny, Y. V. Ivashchenko, I. A. Koseko, and G. A. Avtonomov, "Investigation of physico-chemical phenomena that occur when iron powderfriction on ceramic," Journal of Friction and Wear, vol. 11, no. 1, pp. 143-148, 1990 (Russian).

[66] A. Vutke, E. A. Marchenko, A. Shiling, H. Reinhold, and D. Stemler, "On the quantitative criteria for structural failure of metals in friction," Journal of Friction and Wear, vol. 10, no. 3 , pp. 434-441, 1989 (Russian).

[67] Z. G. Pinchuk and E. G. Shiolovskaya, "Relationship microstructural changes with the kinetics of wear of the surface layer of metal in friction," Journal of Friction and Wear, vol. 10, no. 6, pp. 965-972, 1989 (Russian).

[68] I. Z. Kragelskii, Friction and Wear, Mashinostroenie, Moscow, Russia, 1968.

[69] Y. Y. Meshkov, Physical Basis of Fracture of Steel Structures, Naukova Dumka, Kiev, Ukraine, 1981.

[70] V. N. Antsiferov, S. N. Peshcherenko, A. A. Shatsov, and N. N. Maslennikov, "Effect of pores on fracture of iron," Strength of Materials, vol. 21, no. 2, pp. 161-164, 1989.

[71] O. N. Romaniv, E. A. Shur, A. N. Tkach, V. N. Simin'kovich, and T. N. Kiseleva, "kinetics and mechanism of fatigue crack growth in iron," Physico-Chemical Mechanics of Materials, vol. 17, no. 2, pp. 57-66, 1981 (Russian).

[72] I. V. Kragelskii and V. V. Alisin, Eds., Friction, Wear and Lubrication, vol. 2, Mashinostroenie, Moscow, Russia, 1979.

[73] K. M. Fedorchenko and L. I. Pugina, Composite Sintered Antifriction Materials, Naukova Dumka, Kiev, Ukraine, 1980.

[74] A. M. Ryakhovskii, "Calculation of wear intensity of construction materials under elastoplastic friction-contact interaction," Journal of Friction and Wear, vol. 11, no. 1, pp. 42-48, 1990 (Russian).

[75] L. S. Moroz, Mechanics and Physics of Deformation and Fracture of Materials, Mashinostroenie, Moscow, Russia, 1984.

[76] V. N. Antsiferov, N. N. Maslennikov, and A. A. Shatsov, "Strength and fracture toughness of powder steels," in Proceedings of the Universities. Iron and Steel, no. 3, pp. 124-129, 1989.

[77] V. N. Antsiferov, N. N. Maslennikov, A. A. Shatsov, and V. B. Platonova, "Effect of heat treatment on the crack resistance of powder steel SP50Kh3NM," Metal Science and Heat Treatment, vol. 33, no. 8, pp. 617-620, 1991.

[78] V. N. Antsiferov, N. N. Maslennikov, and A. A. Shatsov, "Now to determine friction coefficients of sintered steels?" Journal of Friction and Wear, vol. 14, no. 6, pp. 1082-1086, 1993 (Russian).

[79] V. N. Antsiferov, N. N. Maslennikov, and A. A. Shatsov, "Friction wearing powder steels without additional feeding lubricant," Journal of Friction and Wear, vol. 15, no. 6, pp. 1022-1027, 1994 (Russian).

[80] V. N. Antsiferov and A. A. Shatsov, "Friction and wear of powder steels under lubricant limited supply conditions," Journal of Friction and Wear, vol. 16, no. 2, pp. 315-322, 1995 (Russian).

[81] V. N. Antsiferov and A. A. Shatsov, "Friction and wear of powder aluminum bronze of optimal composition," Journal of Friction and Wear, vol. 17, no. 2, pp. 56-60, 1996. 
[82] V. N. Antsiferov, T. V. Smyshlyaeva, and A. A. Shatsov, "Selflubricating copper-based pseudoalloy for antifriction and constructional products," Journal of Friction and Wear, vol. 17, no. 4, pp. 497-502, 1996 (Russian).

[83] A. A. Shatsov, "Tribological characteristics of powder steels under boundary friction," Advanced Materials, no. 2, pp. 6973, 2001 (Russian).

[84] A. A. Shatsov, "Prediction of tribological characteristics of powder steels under dry friction," Advanced Materials, no. 5, pp. 71-77, 2000. 

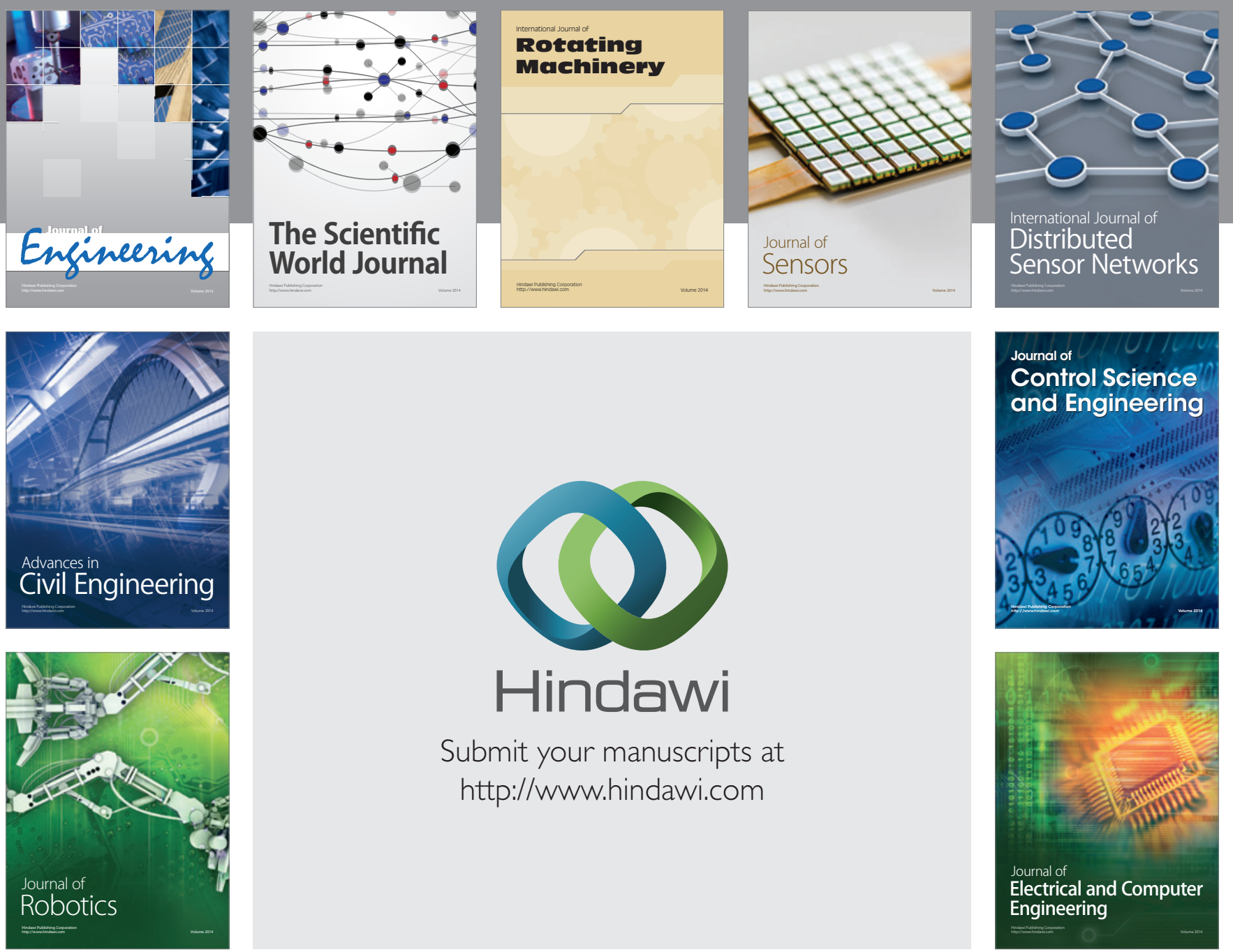

Submit your manuscripts at

http://www.hindawi.com
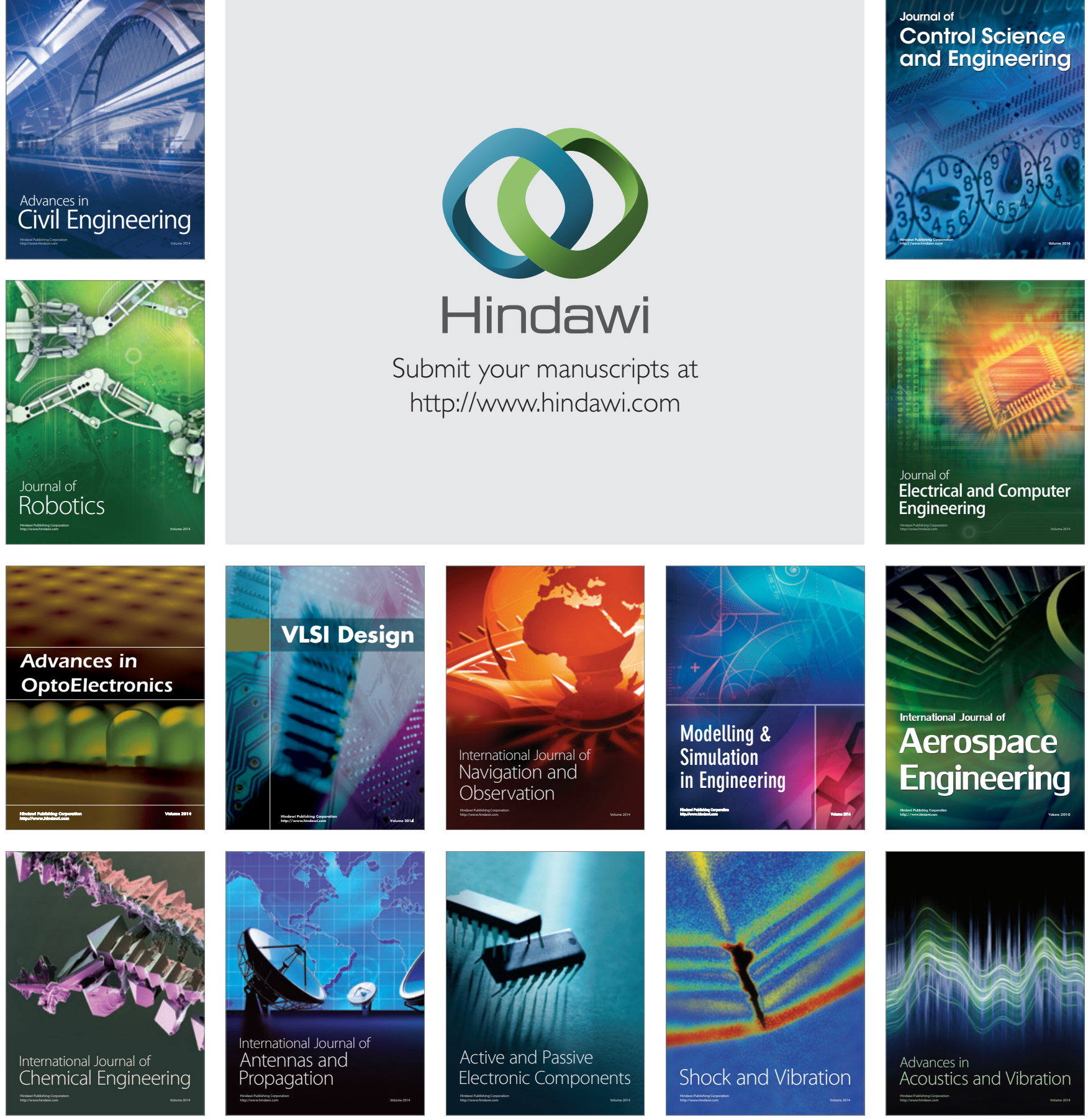